\title{
INGER ENKVIST Y LA EDUCACIÓN ACTUAL*
}

En estas páginas se incluyen los comentarios de los panelistas Diego Ibáñez, Francisco Claro, Cristián Cox, Andrea Rolla y Arturo Fontaine a la exposición que hizo Inger Enkvist ("La Influencia de la Nueva Pedagogía en la Educación: El Ejemplo de Suecia”) durante el seminario efectuado en el Centro de Estudios Públicos el 10 de agosto de 2009. Asimismo, a continuación se reproducen la réplica de la expositora a los comentarios recibidos y su respuesta a las preguntas del público.

Inger Enkvist: Ir contracorriente y rescatar el sentido común Diego Ibáñez Langlois

Comentarios a la presentación de Inger Enkvist en el CEP Francisco Claro

Las prácticas pedagógicas de excelencia y la combinación de paradigmas: A propósito de un análisis crítico sueco Cristián Cox

La necesidad de modelos concretos que se evalúen sistemáticamente para mejorar el sistema educacional chileno

Andrea Rolla

Contra el "pedagogismo"

Arturo Fontaine

Respuesta a los comentarios de los panelistas

Inger Enkvist

Diálogo de Inger Enkvist con el público

* Véase en esta edición el ensayo de la docente y ensayista sueca Inger Enkvist, "La Influencia de la Nueva Pedagogía en la Educación: El Ejemplo de Suecia”. (N. del E.)

Estudios Públicos, 115 (invierno 2009). 


\section{INGER ENKVIST: IR CONTRACORRIENTE} Y RESCATAR EL SENTIDO COMÚN

\section{Diego Ibáñez Langlois}

\section{$\AA_{\text {gradezco a Inger Enkvist su valentía para navegar contra- }}$} corriente, y de más está decir su sensatez y sentido común para desenmascarar las oleadas de "modernidad" que están destruyendo en el mundo la calidad de la educación. De hecho, concuerdo plenamente con ella cuando ha afirmado que la educación — para tantos gobiernos en distintas partes del mundo- se ha convertido en una mercancía política. Es decir, que se toman medidas y se hacen reformas sólo buscando dividendos electorales. Reformas con una pesada carga ideológica, que buscan el aplauso de los correligionarios y que dejen contentos a los que detentan el turno del poder. Reformas en que la calidad es sólo una palabra vacía de contenidos, que se menciona como una anestesia de las conciencias para dejar a todos contentos.

\section{Vértigo de reformas}

También comparto con ella que una de las causas más nítidas del retroceso en los resultados es el vértigo no sereno que experimentan los gobiernos por las reformas educacionales. Ella lo ha constatado en el caso de Suecia. Reformas, nuevas reformas, contrarreformas, megarreformas. Como si la calidad de la educación estuviera atada a los decretos y las leyes del gobierno de turno. En Chile, la jornada única, que suena bien a todos los oídos, en lugar de un progreso se ha convertido en "más de lo mismo". ¡Y qué implacable sucesión de reformas! Los gobiernos de turno siempre quieren "dejar su sello”, y de hecho lo dejan, como un recuerdo triste de su paso. Lo quieren hacer bien, pero terminan borrando con el codo lo que escriben con la mano.

Diego IBÁÑEz. Licenciado en Filosofía y Letras por la Universidad de Navarra; Orientador Familiar por la misma Universidad. Ha dedicado su vida a la dirección de colegios (Mestral, Barcelona; Tabancura, Santiago de Chile). Autor de varios libros. Director de Seduc, director de la revista Hacer Familia. 


\section{Una muestra lamentable: la PSU en Chile}

En nuestro país, como en Suecia, se improvisó una nueva prueba de ingreso a la universidad, sin marcha blanca, sin plan piloto, sin estudios serios, sin el mínimo de profesionalismo que se puede esperar de un Consejo de Rectores, abusando de la palabra equidad, de consignas de moda y de la intromisión de los "ólogos" que se han apoderado de la educación como si les perteneciera. Así, sacaron de debajo de la manga la dichosa prueba que sustituyó a la anterior, mejorable sin duda, pero probada durante años. Las primeras generaciones que rindieron la PSU fueron unos auténticos conejillos de Indias, maltratados por la improvisación y dejados solos en plena tormenta. No contaron con ningún facsímil oficial, no hubo marcha blanca, no se mostró la prueba a los organismos internacionales para que dieran su veredicto. Incluso, los primeros facsímiles se ocultaron por temor a la crítica de expertos. Nada se dijo tampoco que al introducir obligatoriamente los contenidos de los programas del Ministerio se estaba amputando gravemente la libertad de enseñanza, ya que todos los establecimientos educacionales debían adoptarlos a la fuerza para no perjudicar a sus alumnos. Se faltó así el respeto a los alumnos y en una materia muy sensible para nuestra juventud, ya que en ella se juegan el acceso a los estudios universitarios. Y de paso, como otro as debajo de la manga, se impuso un programa de lengua y comunicación que rayaba en la estupidez, incorporando términos técnicos sofisticados y pedantes para nombrar las realidades más pedestres. Se mató así el gusto por la lectura y se dejó fuera la enseñanza de la historia, de la literatura y de las obras clásicas: venían a decir que valía lo mismo Shakespeare que un artículo de un periódico o un programa popular televisivo. La misma redacción del programa elaborado por el Ministerio demuestra la incultura de sus redactores. Y a pesar de que los sucesivos resultados de la PSU han venido demostrando que sólo han aumentado la brecha de inequidad, nada se ha hecho para rectificar. El desacierto ha quedado petrificado en la historia de la educación chilena. He escrito innumerables cartas al director del El Mercurio. Agradezco que siempre hayan sido publicadas. Pero nunca una respuesta. Otra voz que clama en el desierto ya que las autoridades tienen oídos sordos para lo que no les conviene.

No debe extrañar que una masa enorme de niños en nuestro país no comprenden lo que leen y son incapaces de redactar cuatro frases 
coherentes. Para compensar, se les ofrece ahora el miserable obsequio del llamado maletín literario, como curiosa compensación a lo que no se les entrega legítimamente en la sala de clases. ¡Oh educación, penosa mercancía política!

Obvio: la calidad de los profesores

Todos saben, además, que la calidad de educación pasa por la calidad de los maestros, y que éstos, para dar de sí lo que se espera de ellos, deben realizar un trabajo humano y no convertirse en máquinas de hacer clases. En nuestro país son muchos, demasiados, los que no tienen tiempo para el estudio ni para la preparación de sus clases, como tampoco para atender personalmente a sus alumnos. Esos papeles que alguna vez reflejaron la preparación de sus clases ya tienen el color amarillo del tiempo. Esto lleva necesariamente a la rutina, a la pérdida de la ilusión profesional como también al resentimiento y a la creación de una mentalidad burocrática. Es decir, a dar lo mínimo para conservar el puesto. Mal pagados, mal considerados socialmente, e impedidos de realizar un trabajo de calidad, se siguen repitiendo sin mejorar sus clases. Además que es sabido que no son los mejores los que estudian pedagogía en las universidades (los puntajes exigidos son los mínimos), y que éstas - al menos muchas de ellas - tampoco cuentan con los mejores profesores.

\section{Divertirse, no aprender}

Otra de las causas del deterioro que detecta Inger Enkvist es la tendencia a convertir la enseñanza en algo meramente lúdico, atractivo, que entretenga a los alumnos, "que lo pasen bien” en la sala de clases, lo que ha llevado al abuso de creer que el alumno puede aprender sin poner esfuerzo de su parte. Ella se pregunta: ¿jugar o aprender? Si a esto se suma el afán de rebajar la exigencia académica, casi hasta llegar al aprobado obligatorio, los resultados son paupérrimos. En Suecia, en un momento, incluso se rebajó a tres posibilidades la escala de notas. Resultado: el profesor se desentendió de la responsabilidad del aprendizaje y se transformó en un promotor de diversión fácil. Lo más pareci- 
do a un animador de un programa rústico de televisión. Como si a través del juego y la entretención se pudiera aprender un idioma o se pudieran desarrollar habilidades intelectuales.

\section{La convivencia es lo importante}

¿Y qué decir cuando se favoreció la convivencia como meta, en lugar de los conocimientos? Esa prioridad, en vez de formar mejores personas, llevó a un aumento de la violencia. Lo más triste es que todo se hizo de buena fe, basados en teorías "que son presentadas como modernas y científicas” y que están dictando las políticas educacionales en la mayoría de los países occidentales. Corrientes pasajeras que se ponen de moda sin que nadie las pase por el cedazo del pensamiento serio. ¡Y cuántos errores se han cometido bajo la bandera de "la igualdad social”, algo que en sí es válido y atractivo, pero no del modo como se ha llevado a cabo. La igualdad que nivela para abajo, por decreto.

\section{Irrespeto y el culto a la espontaneidad}

Peor todavía si ya no se inculca el respeto y se considera a la disciplina como un valor arcaico, no acorde con los vientos de moda. $\mathrm{Y}$ hablo de una disciplina humana, la misma que un buen padre de familia entiende por buena educación. Si ella no se exige, el profesor pasa a ser el blanco preferido por la juerga y la chacota; disciplina, por otra parte, que es la única que hace posible el trabajo intelectual y la dignidad del docente. En Chile, cada vez son más frecuentes las agresiones a los maestros.

La llamada autodisciplina — que es uno de los objetivos de la disciplina sensata - se va convirtiendo en regla dogmática. Lo que prolifera así no es otra cosa que el comportamiento "espontáneo" de los alumnos dejados a su arbitrio. El niño, al contrario de las ideas románticas de Rousseau, como todos hemos comprobado, puede ser "espontáneamente” cruel e insolente. ¡Cuántos casos de matonaje y violencia injustificada! Si al niño no se le educa y se le señalan límites, queda en el estado del buen salvaje. 


\section{La diosa tecnología}

Más aún: la diosa tecnología ha ingresado en las aulas exigiendo que todos le rindan pleitesía. Como si la calidad dependiera exclusivamente de los medios audiovisuales, independientemente de quién sea el profesor. Así se privilegia — como dice Enkvist— "la búsqueda individual de la información y lo lúdico”, sin la guía inteligente del profesor, que se convierte en un simple "facilitador" de materiales. La internet no guiada se usa como manual. Cada alumno se aventura por su cuenta y riesgo, ya que se le insta "a navegar" con rumbo desconocido. "Tecnología y autonomía del alumno” — dice Enkvist— “eliminan la capacidad de trabajar el pensamiento en clase” y no dejan pie a "la discusión en grupo, puesto que cada cual trabaja en su pantalla; y si todos son autónomos y trabajan en campos diferentes tampoco tienen una base en común que pueda hacer interesante una discusión". "Se supone, además, que el alumno va a poder encontrar un material interesante sobre algo que todavía no conoce. En una palabra, se supone que cualquier alumno, sin preparación alguna, sin madurez, sin disciplina, es un autor de manual en potencia.”

\section{Una especie extraña: el sentido común}

No soy experto ni he estudiado los sistemas educativos como lo ha hecho la rigurosa especialista sueca. Pero he dirigido y asesorado colegios de prestigio durante muchos años, y la experiencia me hace constatar que las conclusiones de Inger Enkvist son de absoluto sentido común, hasta el punto de que son obvias. Ella las puede demostrar con estadísticas: a mí me basta la comprobación de lo que dice con la realidad. Me recuerda el consejo de uno de mis maestros, don Víctor García Hoz, hace años: "De tanto estudiar lo difícil, a los educadores se les han olvidado las verdades de siempre”. Y una verdad de siempre es que con la educación no se juega. Los resultados objetivos son implacables. 
COMENTARIOS A LA PRESENTACIÓN DE INGER ENKVIST EN EL CEP

\section{Francisco Claro}

La doctora Inger Enkvist nos ha remecido con su crítica a la situación educacional en Suecia. Efectivamente los resultados de este país en la prueba internacional PISA 2006 (Programme for International Student Assessment) lo muestran 19 lugares por debajo de su vecino Finlandia en matemáticas y en ciencias, y 9 lugares en lectura, marcando una diferencia que debe resultar enojosa para todo ciudadano sueco.

A juicio de Enkvist, el contraste surge entre dos países con evolución muy diferente en los últimos cuarenta años en el ámbito educacional. Mientras Suecia habría sido dominada por reformas inspiradas en la sociología de la educación y las modernas corrientes constructivistas, Finlandia se habría marginado de estas tendencias manteniendo una política más bien tradicional. Mientras uno desplazó el eje de lo que ocurre en el aula hacia los derechos y el rol protagónico del alumno, el otro mantuvo un énfasis en la buena preparación académica de los maestros, el trabajo de los alumnos en un marco de disciplina y el apoyo de la familia en la educación de los jóvenes. Para la doctora Enkvist la responsabilidad recae en décadas de dominio socialdemócrata, partido que habría inspirado las reformas que condujeron al estado actual de la educación sueca. Así planteado, el análisis de posibles causas del deterioro reviste un alto sesgo teórico-político, que amerita un comentario de igual enfoque que dejamos en manos de expertos.

En Chile también estamos preocupados por los resultados de la educación y se ha generado en torno a ella un debate inédito en nuestra historia. Si nos comparamos con nuestros vecinos geográficos no estamos mal, pero si lo hacemos con países del primer mundo como Suecia, salimos mal parados. En la prueba PISA, Chile aparece 26 lugares por debajo de ese país nórdico en matemáticas, 21 lugares en ciencia y 28 lugares en lectura, cifras suficientemente elocuentes. Pero las diferencias van mucho más allá. Chile dobla en población a Suecia, mientras ésta más que duplica a Chile en ingreso per cápita. En el

Francisco Claro. Ph. D. en Física por la Universidad de Oregon (EE.UU.). Decano de la Facultad de Educación de la P. Universidad Católica de Chile. Miembro de la Academia de Ciencias de Chile. Cátedra Presidencial 1999, Fellow de la American Physical Society. Fundador y presidente de la organización Ciencia para Todos. 
ámbito científico Suecia tiene siglos de tradición, con personajes como Alfred Nobel, Hannes Alfvén, Anders Angström, Svante Arrhenius, Anders Celsius, Johannes Rydberg y muchos otros. En Chile, en cambio, la actividad en ciencia se inicia recién algunas décadas atrás. Estas marcadas diferencias nos impiden asociar muy estrechamente las causas de malos resultados en ambos países, aunque en algunos puntos hay coincidencias, como es el caso de los profesores.

La doctora Enkvist valora particularmente la preparación de los docentes. En Chile se está reconociendo crecientemente su importancia, ya que los profesores son los actores principales del sistema, a cargo del trabajo en aula y muchas veces la dirección de las escuelas. Aunque esto parezca obvio, cuando se trata del diseño de políticas públicas los gobiernos tienden a concentrar su acción en mejorar la infraestructura educacional, la calidad de los edificios, la dotación de las bibliotecas o la presencia de computadores en el aula. El aporte es indudable, pero sólo tiene impacto si primero se cuenta con profesores de calidad. Al terminar sus doce años de escolaridad un joven ha estado más de 12.000 horas frente a un profesor, que ha sido, junto a la familia, principal responsable de su formación como persona y como ciudadano. Es en ese contacto profesor-alumno donde se juega en gran parte el futuro del niño. Asegurar su calidad debe ser la primera tarea por emprender.

Para situar el contexto de la situación del profesorado en el país es útil hacer un poco de historia. Cuando en 1920 se dictó la Ley de Instrucción Primaria que hizo obligatorio asistir a la escuela hasta el cuarto nivel básico, había alrededor de 17.000 profesores para una población de 3,7 millones de personas, es decir, un profesor por cada 217 habitantes. Siguieron a esta ley otras normativas de los años 1929, 1965 y 2003, que hicieron obligatoria la asistencia a las escuelas hasta sexto, octavo básico y cuarto medio, respectivamente, para culminar con la jornada escolar completa de más reciente aplicación (JEC, ver Gráfico $\mathrm{N}^{\circ}$ 1).

El consiguiente aumento en la cobertura llevó el número de profesores a su nivel actual de alrededor de 180.000. Considerando que la población es hoy de 16,9 millones, hay un profesor cada 93 habitantes, lo que significa que, por habitante, hoy hay 2,3 veces más profesores que hace noventa años. Con una tasa de crecimiento promedio de 2.000 profesores por año, desde principios del siglo veinte, en la última década 
GRÁFICO No 1

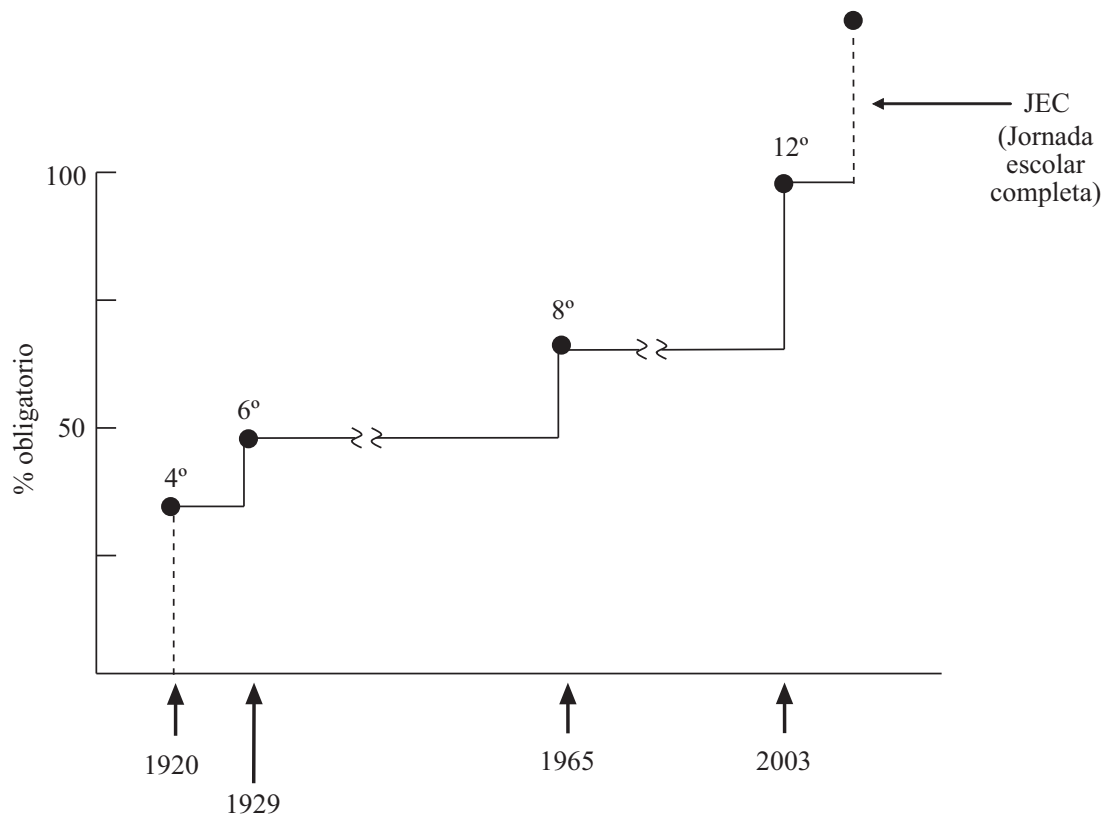

la tasa ha crecido a 4.500 por año. En igual lapso se ha duplicado el número de estudiantes de pedagogía y la oferta de carreras se ha cuadruplicado. Un crecimiento verdaderamente explosivo del sector.

Globalmente, profesores no faltan. Considerando que la población escolar es de 3,6 millones, y que el sistema alberga a 180.000 docentes, significa que tenemos un profesor por cada 20 alumnos aproximadamente, lo que no es un mal índice. Si bien hay sectores deficitarios, como física en enseñanza media —que debiera tener un $50 \%$ más de profesores que los que hay-, el número total es adecuado. Bien, pero ¿cómo es su calidad?

Para evaluar la calidad de un profesor se pueden adoptar dos estrategias: (1) evaluar a sus alumnos, y (2) someter al docente a pruebas de contenidos y habilidades pedagógicas. En los últimos años se ha avanzado en ambos frentes, siguiendo corrientes internacionales lideradas por países europeos y asiáticos. Chile ha tenido el coraje de "mirarse al espejo" a través de diversos instrumentos que cubren ambas estrategias. Las pruebas SIMCE, TIMSS y PISA han evaluado a los alumnos, y el SNED (Sistema Nacional de Evaluación de Desempeño) a 
los profesores. Los resultados a nivel país no son buenos, como lo anotábamos más arriba citando datos de la prueba PISA. Identificar las causas principales no es fácil por la multiplicidad de factores que intervienen en los resultados. Sin embargo, en lo que concierne a los profesores, se puede mencionar algunos aspectos que sin lugar a dudas tienen gran importancia para el juicio crítico de la situación actual. A continuación se enumeran tres.

(1) El crecimiento de la cobertura escolar, provocado por los diversos cambios en la legislación a través del tiempo, no ha estado acompañado por acciones de buen diseño que aseguren que el crecimiento en la demanda de nuevos profesores sea satisfecha por personas altamente calificadas. En los países con mejores resultados los nuevos docentes son reclutados del $10 \%$ superior de su promoción, condición que en Chile estamos lejos de cumplir. Apenas uno de cada veinte de los admitidos a las carreras de pedagogía de las 24 universidades del Consejo de Rectores el 2009 estuvo en dicho segmento. Una vez admitidos, las instituciones donde ingresan no logran compensar significativamente las carencias de los que llegan con mala preparación, como lo demuestran los resultados de la prueba 2008 del programa INICIA.

(2) Las condiciones de trabajo de una buena parte del profesorado no permiten un buen desempeño. Lo más grave es la falta de tiempo para las tareas anexas al desempeño en aula. Con demasiada frecuencia el docente no tiene espacios para preparar sus clases y materiales de apoyo, o para construir instrumentos de evaluación, y luego poner atención al desempeño de cada alumno. Una encuesta de 2001 revela que aproximadamente el $45 \%$ de los docentes de los subsectores de ciencias naturales en enseñanza media tiene más de 30 horas pedagógicas semanales, mientras un $12 \%$ tiene más de 44 horas de contacto con alumnos; en circunstancias de que ningún docente puede servir adecuadamente más de 30 horas pedagógicas semanales. Los pilotos tienen restricciones para volar muchas horas, los choferes de buses las tienen también, pero los docentes no, como si su tarea no fuera vital para la población.

(3) No existe un programa de alto impacto para la educación continua, con el fin de capacitar y renovar conocimientos y prácticas pedagógicas. En Singapur, país que ocupa primeros lugares de desempeño en las pruebas internacionales, los docentes reciben 100 horas 
pagadas de capacitación por año, lo que les permite actualizarse y reflexionar acerca de su desempeño con la holgura y calidad que la tarea requiere.

La inversión estatal en los docentes suele hacerse notar recién a mediano o largo plazo. Por ejemplo, un alza significativa de los sueldos no tiene un efecto inmediato sobre la calidad de la docencia. Su impacto se verá recién cuando ingresen al campo laboral quienes fueron atraídos a la carrera por los mejores salarios, lo que ocurre luego de cinco o más años, y mejorará la educación de algunos niños luego de diez o más. Al mismo tiempo, siendo el sector muy numeroso, cualquier aumento parejo de sueldo significa un gasto enorme. En Chile, duplicar el sueldo de los profesores costaría alrededor de 1,8 millones de millones de pesos al año —unos 3,4 mil millones de dólares—, carga gigantesca para la economía del país. ¿Qué esperanza hay de que un gobierno adopte semejante medida si está preocupado de su reelección en cuatro años?

Es más rentable políticamente invertir en infraestructura, porque es un gasto apreciado por la gente a corto plazo, y porque es por única vez. Sin embargo, suele hacerse sin pensar que ese bien tiene un costo adicional de buen uso que a veces supera la inversión. Dotar de equipamiento de laboratorio de química a un colegio no tiene impacto si no se crean las condiciones para su buen uso: capacitación del docente, incentivos para incorporar eficazmente la nueva estrategia al aula, y tiempo para montar y desmontar el equipamiento en la sala. Lo mismo ocurre con los computadores y las bibliotecas: se convierten en un estorbo a la conciencia escolar si se dota a las escuelas de ellos sin un plan paralelo de apoyo e incentivos para su eficaz utilización.

A la pobre selección que se aplica al ingreso a las carreras de pedagogía se suman problemas estructurales de las instituciones que los forman. Se trata de institutos profesionales y universidades que hasta ahora han titulado a sus egresados sin una certificación de calidad. Hay cambios en marcha que tienden a corregir el problema, como la exigencia de someterse a acreditación y el programa INICIA, que introduce exámenes comunes al final de la carrera. La eficacia de estas medidas dependerá de la calidad y transparencia con que operen los instrumentos de evaluación elegidos, así como de las consecuencias que un mal resultado tenga sobre la institución y sus alumnos. 
En los últimos cuarenta años, las escuelas de pedagogía para la enseñanza media de algunas universidades tradicionales sufrieron un proceso de cambio que las afectó profundamente. Hasta los años sesenta las unidades académicas que las cobijaban eran facultades de filosofía y humanidades, que agrupaban en sus claustros académicos con pasión por la filosofía, la historia, la física, las matemáticas, la educación. Fueron los tiempos de Ricardo Krebs, Mario Góngora, Juan Gómez Millas, Jaime Eyzaguirre, Rubén Toro, Carlos Rivera, Domingo Almendras, Armand Grandjot. Era un entorno donde se estudiaba e investigaba en profundidad las diversas disciplinas, y existía un gran amor y respeto por ellas y su cultivo.

Con la reforma que ocurrió a fines de esa década, estos académicos emigraron a los recién creados institutos de las diversas ciencias y humanidades, abandonando las facultades de educación. Se perdió así una buena parte de la efervescencia intelectual aportada por esos grandes pensadores, que había nutrido hasta entonces la rica vida académica que rodeaba a las escuelas de pedagogía.

Contra lo esperado, los nuevos institutos de historia, de letras, de filosofía, de matemáticas, de física, etc., se distanciaron de los pedagógicos, creándose con el tiempo además un foso de desconfianza y descalificación mutua que impidió el trabajo conjunto y complementario que los estudiantes de pedagogía merecieron. Al desaparecer la influencia de las disciplinas en los diseños curriculares, el afán por la formación pedagógica no tuvo contrapeso y el rol de los contenidos fue perdiendo fuerza.

También las escuelas de profesores primarios sufrieron un gran cambio, al terminarse las escuelas normales en 1967 y desplazarse la responsabilidad de formar docentes a los institutos profesionales y universidades. Esas escuelas solían ser internados que seleccionaban con cuidado a los futuros profesores, donde el estrecho contacto entre docentes y alumnos permitía la fiel transmisión de conocimientos y valores de generación en generación. Se perdió una tradición, una manera de hacer las cosas que tuvo su sabiduría, siendo reemplazada por una estrategia para la formación de profesores que no ha tenido el éxito esperado. También en la educación primaria el afán pedagógico ha sido mayor que el que vigila los contenidos y hoy muchos docentes en ejercicio reconocen que no dominan las materias que deben enseñar a sus alumnos y alumnas. 
Para terminar, quisiera hacer un breve alcance a la fuerte crítica que la doctora Enkvist hace al constructivismo como paradigma del proceso educativo. No cuestiono que una forma extrema de esta tendencia, mezclada con una marcada protección del niño contra toda forma de exigencia y rigor, pueden resultar una mezcla muy dañina. En su crítica, Enkvist se refiere al afán por hacer de la experiencia educativa algo "entretenido", tendencia que sin duda puede llevar a descuidar grandes territorios del aprendizaje que son duros y nada divertidos para algunos. Sin embargo, hay ámbitos en los cuales procurar despertar en cada niño el gusto por lo que hace y aprende en la escuela puede jugar un papel importante para toda su vida. Un ejemplo evidente es el aprecio por la buena literatura, la que se puede gozar universalmente y desde muy niño. El constructivismo no busca la entretención del alumno sino más bien capturar su interés y participación en el aula, objetivo bien diferente.

No se entiende el espectacular avance de la ciencia y la tecnología en los últimos tiempos sin una forma exitosa de transmisión de esos conocimientos y habilidades. En la tradición de enseñanza en este ámbito ha estado presente un constructivismo implícito para evidente beneficio de los alumnos. El método de indagación, por ejemplo, ha sido adoptado por el sistema educacional francés e implementado también en Chile por el Programa ECBI (Enseñanza de las Ciencias Basada en la Indagación). En su diseño hay elementos constructivistas evidentes en el sentido de que busca que cada alumno siga un protocolo, un procedimiento cuidadosamente elaborado, que le permita acceder inductivamente y en forma individual a una noción de la ciencia. Es cierto que no se puede pretender que cada ciudadano reinvente el teorema de Pitágoras o la ley de la gravedad, pero también es cierto que descubrir algo impacta y enamora, situándose en el opuesto de la mera memorización como experiencia educativa. Lo que se descubre no se olvida y la emoción que lo acompaña puede despertar un interés y hasta una verdadera vocación por la ciencia. Ha ocurrido muchas veces en la historia.

Finalmente, uno podrá estar de acuerdo o en desacuerdo con la crítica levantada por la doctora Enkvist. Pero todos debemos reconocer que su discurso nos ha dejado pensativos y preocupados. Es en este ir y venir de las ideas, junto al análisis de la evidencia que surge de la observación del mundo real, el entorno en que habrán de emerger estrategias más acertadas para educar a los niños del siglo veintiuno. 


\section{LAS PRÁCTICAS PEDAGÓGICAS DE EXCELENCIA Y LA COMBINACIÓN DE PARADIGMAS: A PROPÓSITO DE UN ANÁLISIS CRÍTICO SUECO}

\section{Cristián Cox D.}

[L]os investigadores concuerdan en que no existe una nítida y única mejor manera de enseñar. La efectividad de la práctica docente en el aula tiene que ver con la especificidad del ámbito como con la especificidad del objetivo; depende del contexto cultural y de las tradiciones de la profesión ${ }^{1}$.

(OECD, TALIS)

El análisis crítico radical que hace la educadora sueca Inger Enkvist sobre los últimos cuarenta años del desarrollo educativo de su país pone de relieve la centralidad de las ideas y prácticas de los educadores sobre los resultados de la enseñanza. Con niveles de ingreso y oportunidades en educación de los más altos del mundo, Suecia obtiene resultados de aprendizaje inferiores a los de su vecina, e históricamente considerada inferior, Finlandia, e inferiores también a los del selecto grupo de países de excelencia educativa del mundo.

Para Enkvist, todo comenzó a ir mal para la educación, y en especial para la educación de su país, cuando la sociología de la educación y la psicología del aprendizaje (junto a un grupo patentemente disímil de autores como Rousseau, Dewey, Piaget, Foucault y Bourdieu) pusieron al estudiante y sus capacidades e intereses al centro de la preocupación de los pedagogos, en desmedro del conocimiento y la cultura a transmitir. Establecida la hegemonía en Suecia de una pedagogía constructivista y criterios políticos igualitaristas respecto a educación, un conjunto de males íntimamente ligados habrían afectado a su educación: profesores menos preparados en contenidos disciplinarios, currículos menos rigurosos y exigentes, una pedagogía centrada en el aprendiz y sus intereses y motivaciones con profesores no-directivos,

Cristián Cox. Ph. D. Universidad de Londres. Sociólogo, Universidad Católica de Chile. Director del Centro de Estudios de Políticas y Prácticas en Educación de la Universidad Católica de Chile. Director del Programa de Postgrado de la Facultad de Educación de la misma universidad.

${ }^{1}[\mathrm{R}]$ esearchers agree that there is no single, well-defined best way of teaching. The effectiveness of classroom practice is domain specific as well as goal-specific; it depends on the cultural context and professional traditions." (OECD, TALIS, p. 97) 
evaluaciones sin consecuencias, alumnos que no estudian ni tienen disciplina, y, finalmente, resultados de aprendizaje inferiores a las expectativas de su sociedad.

Un gran problema con este tipo de juicios generales acerca de la calidad de un sistema nacional de educación en dos momentos de su desarrollo es que no hay cómo saber con precisión si hace cuarenta años los resultados de aprendizaje del sistema escolar sueco eran superiores a los actuales, ni cómo se hubiesen comparado internacionalmente, por la simple razón de que no había entonces evaluaciones como las actuales pruebas TIMSS y PISA. Más importante, en el mismo período, como ocurre con los sistemas escolares de toda Europa, la educación secundaria de Suecia pasó de ser selectiva a masiva, con lo cual la base de comparación, en la que se fundan los juicios críticos de nuestra autora, cambia de modo sustantivo, complicándolo todo. Porque ¿cómo comparar la pedagogía y el ethos de un sistema que debe producir aprendizaje del currículo nacional para una élite, o si no una élite, una proporción del grupo de edad, con las del mismo sistema cuando debe atender a todo el grupo de edad y hacerse cargo, por tanto, de diferencias socioculturales importantes en las capacidades de adquisición de sus alumnos?

Lo que su punto de vista a mi juicio no aprecia, ni lo hace parte del problema en la forma decisiva que tiene en el tiempo que vivimos, es que, efectivamente, la ambición democrática (que ella identifica como ideología socialdemócrata) de hacer de la cultura y el conocimiento superiores un patrimonio común (contra, por cierto, lo que ella llama 'realismo', aludiendo a que algunos podrían, y otros no, trabajar un currículo exigente) es un desafío educacional enorme, que no puede ser respondido a nivel masivo por la pedagogía tradicional. Ésta descalificó siempre como 'no capaces' a los que no contaban con los códigos culturales que eran prerrequisito para llegar a la abstracción alta. Hoy, justamente, el desafío que define el problema pedagógico contemporáneo es ofrecer unos trayectos formativos que se hacen cargo explícitamente de la ausencia de tales prerrequisitos culturales; no para ignorarlos, no para esquivar el problema del aprendizaje de lo que verdaderamente vale la pena en matemáticas, literatura, historia, ciencias y arte, sino para hacerlos alcanzables a las mayorías. En tal intento por cierto que hay equívocos y caminos sin salida. Algunos de los cuales el análisis de Enkvist contribuye a denunciar. 
Sin embargo, su crítica de lo que llama el 'pedagogismo' no se hace cargo a mi juicio de lo esencial de la situación contemporánea en educación, al propugnar la simple vuelta atrás, a un tiempo pretérito e irrecuperable —que no debiera ser base de orgullo, porque se basaba en la exclusión-, cuando una pequeña fracción del grupo de edad llegaba a la secundaria superior, y no había mayor distancia entre los códigos de la comunicación escolar de un currículo académico exigente y unos estudiantes provenientes de familias y contextos con códigos socio-lingüísticos elaborados (Bernstein, 1971). Hay muchas formas de responder en forma efectiva a este difícil desafío, y de ello son muestra las diferencias en métodos como en ethos promovidos por la educación, de sistemas inclusivos excelentes, que son tanto de tradiciones políticas liberales (Canadá), como socialdemócratas (Finlandia), de bases ético-culturales occidentales (como los mencionados), o confucianas (Singapur). En unos y otros, la visión profesional mainstream acerca del que aprende y los requisitos que plantea a la enseñanza y sus métodos es generalmente convergente. Es en verdad difícil encontrar un sistema educativo nacional de preparación de profesores, o de definiciones sobre currículo y evaluación, en que las ideas de lo que algunos han rotulado como el modelo PVK (por Piaget, Vygotsky y Kohlberg) no tengan una influencia central (Naumann, 2005) ${ }^{2}$. Las ideas de estos autores, y sus variantes, han predominado en el pensamiento educacional sobre aprendizaje cognitivo y moral de los niños por los últimos cincuenta años, con impacto indiscutible en las categorías interpretativas del profesorado contemporáneo sobre enseñanza y aprendizaje. Lo interesante, sin embargo, es que, junto con estas interpretaciones o creencias, las prácticas docentes predominantes en el mundo, con independencia de culturas y niveles de desarrollo de los países, son las 'centradas en el profesor' y se caracterizan por sus rasgos tradicionales.

Lo señalado, en sus dos dimensiones — creencias y prácticas-, es lo que acaba de confirmar la prueba internacional de la OCDE,

2 Piaget descubrió la existencia de fases de desarrollo cognitivo en los niños de decisivas consecuencias para la educación; Vygotsky contribuyó con el concepto de que el conocimiento de un individuo no es transmitido de una persona a otra sino activamente construido, o más bien co-construido en interacciones con otros individuos dentro de un contexto sociocultural definido — dando pie al principio fundante del constructivismo en educación-; Kohlberg teorizó e investigó cómo los conceptos de fases de desarrollo —universales— se aplicaban al desarrollo moral. 
Teacher and Learning Internacional Survey (TALIS), que encuestó a profesores de 23 países acerca de sus condiciones de trabajo, sus representaciones, valores y actitudes ${ }^{3}$. El estudio midió las percepciones docentes sobre enfoques de la enseñanza. Para esto construyó dos índices, uno sobre visión constructivista de la docencia, y otro sobre visión de la docencia como transmisión directa, basados en las respuestas de los docentes a los ítems del siguiente Recuadro $\mathrm{N}^{\circ} 1$ :

RECUADRO N 1

Visión constructivista de la docencia

- Mi rol como docente es facilitar la búsqueda e investigación que realizan los estudiantes.

- Los estudiantes aprenden mejor cuando encuentran sus propias soluciones a los problemas

- Debe permitirse a los estudiantes buscar sus propias soluciones a los problemas que el docente les exponga.

- Los procesos de reflexión y razonamiento son más importantes que los contenidos curriculares específicos.

\section{Visión de la docencia como transmisión directa}

- Los buenos docentes demuestran la forma correcta de resolver un problema.

- La enseñanza debe ser construida alrededor de problemas con respuestas claras y correctas, y en torno a ideas que la mayoría de los estudiantes puede captar rápidamente.

- El grado en que los estudiantes aprenden depende de sus conocimientos previos, por eso la enseñanza de hechos es tan necesaria.

- Para lograr una enseñanza efectiva generalmente se necesita una clase en silencio.

Fuente: OCDE: Creating Effective Teaching and Learning Environments: First Results from TALIS, 2009, Recuadro 4.1.

El Gráfico No 1 muestra que en todos los países del estudio, salvo Italia, hay un general predominio de los presupuestos constructivistas sobre cómo debe ser la docencia. En la mayoría de los países los profesores creen que su tarea no es simplemente presentar hechos y

${ }^{3}$ Los cuestionarios de TALIS fueron aplicados a 78.000 docentes en total (de unas 200 escuelas por cada uno de los 23 países participantes), en 2007 y 2008. Los países participantes fueron: Austria, Australia, Bélgica, Brasil, Bulgaria, Corea del Sur, Dinamarca, Escocia, España, Estonia, Eslovenia, Eslovaquia, Hungría, Irlanda, Islandia, Italia, Lituania, Malasia, Malta, México, Noruega, Polonia, Turquía. Cfr. OCDE, Creating Effective Teaching and Learning Environments: First Results from TALIS (2009). 
GRÁFICO N ${ }^{\circ}$ 1: PERFILES POR PAÍSES DE CREENCIAS DE LOS DOCENTES ACERCA DE LA NATURALEZA DE LA ENSEÑANZA Y EL APRENDIZAJE (2007-2008)

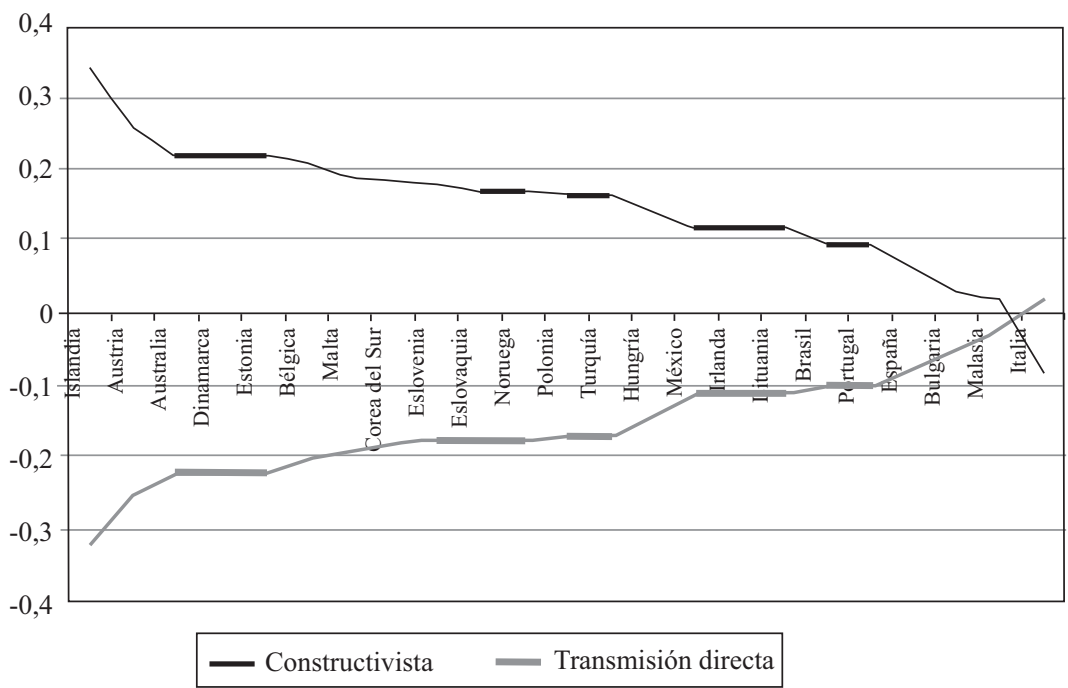

Nota: Los puntajes en el eje vertical corresponden a 'puntajes ipsative' —abordaje estadístico para estandarizar respuestas individuales manifestadas como preferencias entre dos o más opciones, reduciendo los efectos de sesgo de respuesta. Los promedios para los dos índices son cero para cada profesor, y por lo tanto el promedio para los dos índices por país también es igual a cero. El puntaje resultante para un profesor corresponde al apoyo relativo al índice de que se trate, o la posición relativa del individuo en un índice con relación al otro índice. Valores positivos indican que un conjunto de creencias recibe un apoyo relativo más fuerte que el otro.

Fuente: OECD: Creating Effective Teaching and Learning Environments. First Results from TALIS, 2009. Figura 4.2, p. 95.

dar a los estudiantes la oportunidad de que practiquen, sino más bien que deben apoyar a sus estudiantes en actividades que los lleven a construir su conocimiento.

Más allá de este acuerdo general, hay diferencias entre los países en el grado o fuerza con que se presenta esta visión. La preferencia constructivista es más fuerte en Austria, Australia, Bélgica, Dinamarca, Estonia e Islandia, y mucho menos en Malasia, sur de Europa y los dos países de Latinoamérica que participaron en el estudio, Brasil y México. 
Pero ¿qué ocurre si de las creencias se pasa a las prácticas? El estudio TALIS pidió a los profesores estimar la frecuencia de trece prácticas ("en la segunda clase de los días martes en su disciplina principal”) en una escala de 5 puntos, desde "nunca o casi nunca” a “en casi todas las clases", las que fueron agrupadas en los tres índices siguientes:

- $\quad$ Prácticas tradicionales, fueron medidas con cinco ítems: fijación explícita de metas de aprendizaje, revisión de tareas para la casa, chequeo de cuadernos de ejercicios, presentación de una síntesis de lo enseñado en la lección anterior al inicio de cada clase, chequeo a través de preguntas en clase del grado de comprensión de la lección.

- $\quad$ Prácticas orientadas al estudiante, fueron medidas con cuatro ítems: trabajo en grupos pequeños para alcanzar soluciones comunes a un problema, asignación de tareas diferentes a los estudiantes según sus habilidades, autoevaluación de los estudiantes, y participación de los estudiantes en la planificación de actividades del grupo.

- $\quad$ Prácticas alternativas, también fueron medidas con cuatro ítems: los estudiantes trabajan en proyectos que toman al menos una semana completar, elaboración de un producto, producción de ensayos, actividades de debate en clase.

El Gráfico No 2 muestra que las prácticas tradicionales son las más frecuentemente empleadas en todos los países participantes. Las medias para este índice son más altas que las correspondientes a los otros dos tipos de prácticas. Asimismo, 'prácticas alternativas' son menos frecuentes que las 'prácticas orientadas a los estudiantes' en todos los países participantes. Esto implica que los profesores en diferentes regiones del mundo, con marcadas diferencias culturales y en sus niveles de desarrollo, en promedio, a lo que más recurren es a la fijación explícita de metas de aprendizaje, revisión de tareas para la casa, chequeo de cuadernos de ejercicios, presentación de síntesis de lo enseñado en la lección anterior al inicio de cada clase, y chequeo a través de preguntas en clase del grado de comprensión de la lección. Menos frecuentemente permiten codeterminación por los estudiantes de las actividades de clase, emplean agrupamientos por habilidad y dan a los estudiantes tareas adaptadas individualmente; y aún más raramen- 
GRÁFICO Nº 2: PERFIL DE LAS PRÁCTICAS DOCENTES EN LA SALA DE CLASES (2007-2008)

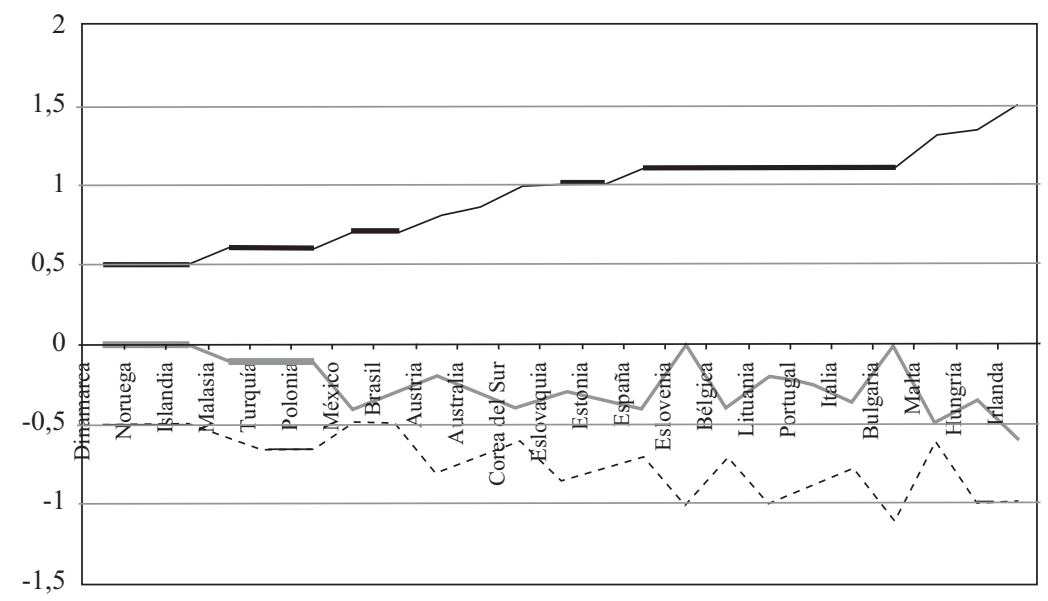

Prácticas tradicionales $\longrightarrow$ Prácticas orientadas al estudiante --- Prácticas alternativas

Nota: Los países se ordenaron por la frecuencia relativa con que sus profesores realizan los tres tipos de actividades en clase: prácticas tradicionales, prácticas orientadas al estudiante, prácticas alternativas. Así, los profesores en Dinamarca adoptan los tres tipos de prácticas en forma relativamente frecuente (y comparable), mientras que en Irlanda utilizan las prácticas tradicionales con mucho mayor frecuencia que los otros dos tipos de prácticas.

Fuente: OECD: Creating Effective Teaching and Learning Environments. First Results from TALIS, 2009, Figura 4.4, p. 98.

te recurren a la asignación a los estudiantes de proyectos prolongados, debates y la elaboración de ensayos y de productos.

La evidencia reseñada ayuda a ubicar la crítica de Enkvist al constructivismo y a sus versiones en el sistema escolar sueco, en un cuadro más amplio en que es necesario distinguir interpretaciones y creencias, de prácticas. Mientras las visiones e interpretaciones constructivistas sobre cómo aprendemos, provenientes de las ciencias cognitivas, parecen incontrarrestadas entre los docentes, las prácticas predominantes mezclan rasgos de 'directividad docente' (enseñanza tradicional) con rasgos de 'iniciativa y actividad de los estudiantes' (docencia 'constructivista'). Esta mezcla, poco apreciada y tematizada por el campo nacional de la formación inicial de profesores, que tiende a pensar 
y enseñar sobre estas materias en términos de 'paradigmas' y sus rasgos excluyentes — se 'es' tradicional o constructivista-, y que no figura tampoco en el marco interpretativo de Inger Enkvist, es sin embargo lo que una y otra vez aparece en la literatura contemporánea como el retrato de la excelencia pedagógica.

Así ocurre con lo que describe Lee Shulman al inicio de su muy influyente artículo "Knowledge and Teaching: Foundations of the New Reform” (2004) ${ }^{4}$, intentando retratar las clases de literatura de una profesora excelente:

Nancy era una profesora muy activa, cuyo estilo de enseñanza en el aula incluía un alto grado de interacción con sus alumnos mediante la lectura recitada de pasajes de obras literarias y, a su vez, debates más abiertos. Ella actuaba como si dirigiera una sinfonía, planteando preguntas, sondeando a los alumnos para obtener puntos de vista alternativos, sonsacando opiniones a los tímidos y al mismo tiempo moderando a los más estrepitosos. Pocas cosas ocurrían en la sala de clases en las que no interviniera Nancy, controlaba el ritmo de las actividades en el aula graduando el progreso de la lección, ordenando, estructurando y extendiendo el contenido [...].

Nancy empleaba [un] marco conceptual en sus clases para ordenar secuencialmente el material y las preguntas a formular. Ella enseñaba explícitamente a sus alumnos sobre el marco conceptual a lo largo del semestre, ayudándolos a servirse de él como un andamiaje para que ellos mismos organizaran su estudio de los textos y revisaran sus propias reflexiones. Si bien como maestra mantenía un férreo control del discurso en la clase, sus objetivos didácticos consistían en liberar la mente de sus alumnos por medio de la lectura, y que a la larga pudieran usar las grandes obras de la literatura para iluminar sus propias vidas. Cualquiera fuera la obra que abordara en sus clases, ella sabía cómo organizarla, cómo enmarcarla para la enseñanza, cómo dividirla adecuadamente para asignar tareas y actividades. Parecía tener en su cabeza un índice de esos libros que había analizado con tanta frecuencia en sus clases - The Red Badge of Courage de Stephen Crane, Moby Dick, La Letra Escarlata, Las Aventuras de Huckleberry Finn-, con los episodios clave organizados mentalmente para diversos fines pedagógicos, distintos niveles de dificultad, diferentes tipos de alumnos, variados tipos de temas o

${ }^{4}$ Publicado en Estudios Públicos N 83, 2001: “Conocimiento y Enseñanza”. 
énfasis. La combinación entre comprensión de la materia y destreza pedagógica que se observaba en Nancy era simplemente deslumbrante. (Shulman 2004: 219-221.)

La sinfonía que era capaz de conducir y realizar Nancy ¿en qué paradigma se ubica? $\dot{¿}$ Tradicional o constructivista?

Con otras bases teóricas y con el foco puesto sobre las relaciones profesor-alumno en el trabajo de un texto de literatura en una clase del nivel secundario de medio popular, la formadora de profesores inglesa Jill Bourne (2004) describe otro cuadro de excelencia en aula, impactantemente similar respecto al juego entre conocimiento de los estudiantes y el conocimiento al que se los hace acceder, puestos en relación por una conducción docente rigurosa a la vez que flexible respecto a quién controla el sentido, ritmo y modalidad del intercambio.

Por gran parte de la clase la profesora permanece estática, sentada formalmente y erecta tras su escritorio. Los estudiantes tratan de responderle en forma igualmente formal; ésta no es una conversación casual. En el incidente crucial que quiero examinar, sin embargo, su postura física cambia tanto como su discurso, mientras, como quiero sugerir, ella pasa la interpretación a la clase, utilizando el conocimiento de ellos para iluminar el texto, y el texto para iluminar sus vidas. La relación en la clase cambia mientras se mueve del texto a la experiencia de ellos, requiriendo una respuesta personal, luego usa su experiencia para ayudarles a entender el texto; finalmente dejando nuevamente el texto para invitarles a reevaluar su propia experiencia desde una perspectiva nueva.

Esto es indicado no sólo verbalmente en un cambio del discurso académico y formal (vertical) al informal (horizontal), sino también por un significativo cambio en su postura y posición en la clase. Ella camina hacia el costado de la sala y se sienta en la cubierta de un pupitre, señalando abiertamente a la clase un cambio en la clasificación y el enmarcamiento del evento [...]. (Bourne, 2004: 69.)

La 'danza' entre los dos discursos ('horizontal' y 'vertical') ${ }^{5}$ aludidos, y el cambio de los modos de interacción (control), ¿corresponden a un profesor 'directivo' o a uno 'facilitador'?

${ }^{5}$ El último trabajo de Basil Bernstein formaliza la distinción entre el conocimiento del sentido común, plasmado en un discurso 'horizontal' que es "local, segmentado, dependiente de contexto, tácito, multinivel, a menudo contradictorio entre contextos pero no dentro de contextos”, y el conocimiento —que comunica la institución escolar- 
Creo que se trata en ambos casos de interrogantes equivocadas. Tan obvio es el pasaje de ambas profesoras entre distintas formas de enseñar y comprometer a los estudiantes en su aprendizaje y crecimiento, al interior de una trama relacional y discursiva, que es tanto de enseñanza tradicional como de exploración y descubrimiento por los estudiantes. También son preguntas equivocadas para la sistematización sobre los hallazgos acerca de como aprendemos quizás más completa y consensual en el conjunto del campo de las ciencias cognitivas y de la educación en Estados Unidos, sistematizada por Bransford et al., en How People Learn (2003), cuya afirmación fundamental sobre las metodologías de enseñanza es que las ventajas relativas de unas y otras dependen de los propósitos, contenidos y contextos de la enseñanza.

\begin{abstract}
Preguntarse por cuál es la mejor técnica de enseñanza es análogo a preguntarse por cuál es la mejor herramienta —un martillo, un destornillador, un cuchillo, o unas tijeras-. En la enseñanza como en la carpintería, la selección de las herramientas depende de la tarea entre manos y los materiales con los que se esté trabajando. (Bransford, J. D., A. L. Brown, \& R. R. Cocking, 2003: 22.)
\end{abstract}

\title{
Paradigmas pedagógicos y realidades nacionales
}

Nuestro país no participó en el estudio TALIS y no sabemos cómo se distribuyen los docentes, tanto en términos de sus visiones como de sus prácticas, respecto a las distintas escuelas de pensamiento o paradigmas pedagógicos. El sentido común educativo señala, sin embargo, la existencia de un discurso y enseñanza coherentemente constructivistas por parte del campo de las instituciones formadoras de profesores, por un lado, y prácticas que combinan algunos elementos de esta visión (como el trabajo grupal) ${ }^{6}$, sobre una trama de metodolo-

plasmado en un discurso 'vertical', que “toma la forma de una estructura explícita, sistemáticamente sujeta a principios, jerárquicamente organizada, como en las ciencias, o que toma la forma de una serie de lenguajes especializados” (Bernstein, 1999: 159).

${ }^{6}$ Martin Carnoy y colegas compararon en 2000 las prácticas de aulas en clases de matemáticas de básica de Cuba, Brasil y Chile. El análisis de videos de clase permitió medir que en Chile el 34,6\% del total del tiempo, contra 29,6\% y 11,3\% para Brasil y Cuba, respectivamente, era empleado en trabajo grupal; y que sólo el 6,5\% del mismo lo era en trabajo individual (copiando instrucciones, resolviendo problemas, verificando trabajos), contra 22,5\% y 40,9\% para Brasil y Cuba. 
gías tradicionales. Respecto a esta combinación, poco estudiada $-\mathrm{y}$ probablemente lejos del blanco (constructivismo consistente) al que apuntan las críticas de Inger Enkvist-, el problema fundamental es el de su baja eficacia; el de sus conocidos problemas para producir aprendizajes, tal cual lo diagnosticó la OECD en su informe sobre las políticas educacionales de los noventa (OECD, 2004), como los trabajos de investigación nacionales que se han acercado a diagnosticar prácticas docentes en medios de pobreza (UNICEF, Mineduc, 2004; Eyzaguirre y Fontaine, 2008).

Por su parte, la normativa oficial del país, tanto curricular como evaluativa, respecto a la polaridad metodológica 'tradicional' y 'constructivista', a diferencia de muchos países de Latinoamérica, y de las definiciones respectivas del currículo español, no se manifiesta por la bondad intrínseca de ninguno de los paradigmas. En vez, concibe la dimensión metodológica como contingente con propósitos, contenidos y contextos. Así, en la evaluación de desempeño docente no se considera como criterio que el trabajo sea o no en grupo, o que el profesor en sus diseños y fundamentación de los mismos en la elaboración del 'portafolio' de evidencia que el sistema evaluativo obligatorio exige para todos los docentes de la dependencia municipal, conciba o no su propio rol como 'facilitador' o 'directivo'?

\section{Constructivismo en contextos de pobreza}

La crítica de Enkvist a lo que sería la sumisión de la enseñanza sueca a las necesidades y motivaciones de sus estudiantes, con olvido del trabajo riguroso requerido por el estudio de las disciplinas escolares, señala a la sociología, y a una de sus figuras mundiales, Pierre Bourdieu, como responsables de tal situación. Hay aquí un malentendido de base, que importa señalar porque tiene implicancias que van más allá de los juicios, errados o no, de la educadora sueca. El malentendido es sobre el rol que tiene, en las categorías interpretativas del profesorado,

${ }^{7}$ En cambio, son criterios que sí se consideran: manejo del tiempo, explicación del objetivo de la clase y un cierre de lo que se aprendió; que las preguntas de los estudiantes sean tomadas en cuenta; que haya consistencia entre el foco de las actividades y el o los objetivos de la misma. Fuente: entrevista del autor con profesionales de MIDE-UC, participantes en sistema de evaluación "Docente Más”, del Ministerio de Educación. 
la comprensión de los requisitos socioculturales que diferentes grupos sociales plantean a una comunicación pedagógica eficaz. A diferencia de lo que plantea Enkvist, la sociología es la disciplina que aporta el conocimiento de tales requisitos y su traducción en demandas metodológicas específicas al quehacer del profesor en el aula. No para celebrar el sentido común, los lenguajes y los intereses de cada grupo social presente en las aulas (esencia del 'populismo educativo'), sino para tomar éstos como punto de partida para llegar a las metas de aprendizaje comunes definidas por un currículo nacional. Desde esta perspectiva, ¿cuáles son los requerimientos a la pedagogía que plantean los grupos pobres? En forma opuesta a lo que interpreta la educadora sueca, los dos sociólogos de la educación más influyentes de fines del siglo XX, Pierre Bourdieu y Basil Bernstein, respondieron, con sus investigaciones empíricas y su teorización, argumentando la necesidad de una pedagogía centrada en la enseñanza explícita por el docente, a la que el primero llamó 'pedagogía racional' (Bourdieu y Passeron, 1964) y el segundo, 'pedagogía visible' (Bernstein, 1975). Ambos demostraron que una pedagogía 'implícita' o 'invisible', en que la autoridad y el control del docente se eufemizan, y en que los criterios sobre los que se quiere educar quedan ocultos, porque [están] 'subentendidos' por estudiantes que ‘ya saben’ (porque [son] portadores de unos códigos absorbidos en la socialización familiar), profundizaba la brecha entre los hijos de los grupos manuales y los códigos de la escuela. "Nadamos en un mar de confusión” declaró Bourdieu una vez, si creemos democratizar la educación y al mismo tiempo no tenemos respuestas adecuadas en la comunicación pedagógica que requiere el mundo pobre para poder tener acceso a los códigos universales que la institución escolar está en principio comprometida a asegurar.

La evidencia sobre la presencia internacional extendida de la mezcla de métodos en las prácticas del profesorado, los retratos de la excelencia en aula presentados, y lo planteado finalmente sobre lo que la sociología de la educación ha encontrado respecto a los requerimientos pedagógicos de la eficacia educativa en contextos de pobreza, creo que constituyen cuestionamientos contundentes a la visión de la pedagogía y la formación inicial de profesores en términos de dos paradigmas y su cancelación ideológica mutua, demandando formas alternativas de abordar el problema. 


\section{REFERENCIAS}

Bernstein, B. (1971): Class, Codes and Control, Vol. I. Theoretical Studies towards a Sociology of Language. Londres: Routledge and Kegan Paul.

(1975): "Visible and Invisible Pedagogies". En B. Bernstein, Class, Codes and Control, Vol. III, Towards a Theory of Educational Transmissions. Londres: Routledge and Kegan Paul.

(1999): "Vertical and Horizontal Discourse: An Essay”. En British Journal of Sociology of Education 20 (2): 157-73.

Bourdieu, P., J. C. Passeron (1964): Les Heritiers. Les Étudiants et la Culture. París: Les Editions de Minuit.

Bourne, J. (2004): “Framing Talk: Towards a 'Radical Visible Pedagogy’”. En J. Muller, B. Davies and A. Morais (eds.), Reading Bernstein, Researching Bernstein. Londres: Routledge Falmer.

Bransford, J. D., A. L. Brown \& R. R. Cocking (2003): How People Learn: Brain, Mind, Experience, and School. National Academy Press, 8a edición.

Carnoy, M., A. Gove, J. Marshall (2003): "Explaining Differences in Academic Achievement in Latin America: Qualitative Evidence from Brazil, Chile and Cuba”. Mimeo. Stanford University.

Enkvist, I. (2009): "La Influencia de la Nueva Pedagogía en la Educación: El Ejemplo de Suecia”. En Estudios Públicos 115 (invierno 2009).

Eyzaguirre, B. y L. Fontaine (2008): Las Escuelas que Tenemos. Santiago: CEP.

Naumann, Jens (2005): TIMSS, PISA, PIRLS and Low Educational Achievement in World Society. En Prospects, Vol. XXXV, N 2, Ginebra, UNESCO.

OECD (2004): Revisión de Políticas Nacionales de Educación. Chile. París: OECD.

OECD (2009): Creating Effective Teaching and Learning Environments. First Results from TALIS. París: OECD.

Shulman, Lee (2004): “Knowledge and Teaching. Foundations of the New Reform”. En L. Shulman, The Wisdom of Practice. San Francisco: Jossey-Bass. [Versión en castellano con el título "Conocimiento y Enseñanza”, en Estudios Públicos 83, 2001.]

UNICEF, Mineduc (2004): ¿Quién Dijo que No Se Puede? Escuelas Efectivas en Sectores de pobreza. Santiago. 


\section{LA NECESIDAD DE MODELOS CONCRETOS QUE \\ SE EVALÚEN SISTEMÁTICAMENTE PARA MEJORAR \\ EL SISTEMA EDUCACIONAL CHILENO}

\section{Andrea Rolla}

Este ensayo es una respuesta al de la doctora Enkvist, que cuenta la historia de la educación en Suecia que, desde su punto de vista, consiste en gran parte en errores cometidos en las últimas décadas. Un problema primordial, Enkvist propone, es la nueva pedagogía, que ha resultado en que los alumnos y alumnas pasen más tiempo en el sistema escolar pero aprendiendo menos. Ofrece una crítica de distintas corrientes de pensamiento dentro del ámbito de la educación, como, por ejemplo, el constructivismo y la sociología de la educación, señalando que el problema de la escuela moderna sueca está en pretender que la escuela debiera lograr disminuir las diferencias sociales entre los alumnos y alumnas y que dejó de exigirles a los alumnos y alumnas. Tiene esperanzas en el futuro en base a legislación que se ha aprobado recientemente en su país que aumenta las exigencias para la formación docente y en señalar las responsabilidades de todos los actores del sistema educacional sueco.

La doctora Enkvist hace una revisión sistemática de la historia de la educación en su país en los últimos cien años, lo cual es muy importante para entender el estado actual de la educación en cualquier país. Además, hace un buen diagnóstico de las posturas radicales sobre la pedagogía y el sistema educacional moderno que no han ayudado a reformar la educación ni en su país ni en otros. Es un aporte valioso comparar los errores de la educación sueca con los éxitos de la educación finlandesa, como hace la doctora de forma convincente. Es importante saber lo que hay que hacer versus lo que no hay que hacer en materia de política pública.

ANDREa Rolla. Doctora en Educación, Universidad de Harvard. Magíster en investigación educacional, Universidad de Oxford. Licenciada en letras y profesora de básica de la Universidad de Princeton. Investigadora Asociada del Center on the Developing Child y la Facultad de Educación de la Universidad de Harvard y directora general del proyecto Un Buen Comienzo, estudio experimental de capacitación docente que busca mejorar la calidad de la educación parvularia en Chile y representa una alianza entre la Universidad de Harvard, Fundación Educacional Oportunidad y la Universidad Diego Portales. 
La mayor preocupación que me genera este texto es la elaboración de las visiones personales de la educación de la doctora Enkvist, lo cual hace difícil evaluar la veracidad de sus comentarios, en vez de sustentar sus opiniones con ejemplos de investigación empírica. Por ejemplo, la doctora señala en su ensayo que "varias investigaciones han mostrado que muchos alumnos con problemas de aprendizaje aprenden más y mejor en un grupo propio [en educación diferencial]”. La doctora Barbara Foorman, en un resumen que describe en detalle estudios de evaluación de intervención con niños y niñas con dificultades de lectura en distintos países angloparlantes, señala que la mejor intervención para niños y niñas con dificultades de lectura es temprana, ojalá antes del comienzo de la primaria o el primer año de enseñanza básica, y que la mejor intervención es en la sala general donde se enseñe bien lenguaje y lectura y no excluyendo a grupos de niños y niñas con dificultades de lectura del aula regular para situarlos en educación diferencial (Foorman, 2003). Concretamente, discrepo de que la investigación haya señalado que los que tienen dificultades de lectura aprenden mejor en grupos separados en educación diferencial. Sugiero explicitar las citas de las investigaciones que dicen lo contrario en este caso específico y en general utilizar el cuerpo de la investigación empírica (no solamente un estudio puntual) para informar y respaldar las opiniones personales donde existe dicha investigación.

Ahora me enfocaré más específicamente en los puntos en que discrepo con la doctora o que encuentro que faltaron si uno tratara de aplicar su diagnóstico al contexto chileno, con el fin de entrar en diálogo con su texto. Prefiero aplicar mis comentarios al contexto chileno en el cual se mueve el público del Centro de Estudios Públicos de Chile. Me parece importante llegar al fondo de cuáles son los problemas hoy en día en el contexto educacional chileno, tomando en cuenta el diagnóstico que hace la doctora Enkvist de su país. Yo diría, tomando en cuenta el ensayo de la doctora, que en Chile hay cuatro problemas importantes:

1. El problema no está en el constructivismo sino más bien en que no se ha logrado que se implementen mejores prácticas pedagógicas a nivel de sala.

2. Necesitamos ir más allá de las críticas, ideologías y los diagnósticos, y evaluar distintos modelos de intervención y llegar a un consenso acerca de qué modelos tienen buenos resultados en el contexto nacional. 
3. Deberíamos crear una ciencia de cómo llevar las intervenciones exitosas a escala y no solamente quedarnos con proyectos piloto que funcionan bien en pocos lugares.

4. Disminuir los efectos nocivos de la vulnerabilidad social implica esfuerzos intersectoriales ambiciosos, como, por ejemplo, colaboraciones entre los sectores que se enfocan en temas de educación, salud, vivienda, etc.

El problema no está en el constructivismo sino más bien en que no se ha logrado que se implementen mejores prácticas pedagógicas a nivel de sala

El "problema” del constructivismo no está en la elaboración de la teoría, como se podría entender de los argumentos de la doctora Enkvist, sino más bien en su aplicación. Los textos originales que trabajan temas del constructivismo no tratan de delinear una pedagogía clara. El problema más bien se ha producido cuando se ha intentado crear una tiranía del constructivismo que se opone a cualquier trabajo sistemático de contenidos con la enseñanza explícita del docente. El problema es definir contenidos con altos niveles de exigencia, tener expectativas más altas de nuestros niños y niñas, y lograr que se implementen sistemáticamente procesos que favorezcan el aprendizaje.

Yo concuerdo con la doctora Enkvist en que si el constructivismo implicara que el alumno tuviera que aprender por su cuenta, sin ninguna mediación de un adulto, estaría equivocado. Solamente me gustaría señalar que un mensaje primordial de los textos originales de Vygotsky (por ejemplo, Vygotsky, 1978), una de las personas más asociadas al constructivismo, es la importancia de la mediación de un adulto para la construcción de los conocimientos. Por lo tanto, el error del constructivismo no está en sus bases conceptuales, sino más bien en la aplicación de dicha teoría a la práctica. Como casi en todos los debates que tenemos en las ciencias, se necesita un equilibrio entre el proceso significativo de aprendizaje del niño o niña y la guía de un adulto. $\mathrm{Y}$ al contrario, yo sugeriría que los docentes chilenos se han apropiado de un discurso constructivista en cuanto a la descripción de su pedagogía en la enseñanza primaria y media pero que no hay evidencia de que hayan cambiado sus prácticas pedagógicas. Entonces hay 
una diferencia entre lo que se pide desde el nivel de políticas públicas y lo que se implementa en sala, lo cual ha resultado en el fracaso de la reforma educacional chilena (Raczynski \& Muñoz, 2007). En realidad, da lo mismo si la reforma educacional chilena fuera constructivista o no; lo que ha quedado claro es que la reforma no logró mejorar ni las prácticas pedagógicas de los docentes ni los resultados de los alumnos y alumnas de forma significativa.

Necesitamos cada vez mayor cantidad de evaluaciones más rigurosas de modelos innovadores y de políticas públicas en educación

Me parece valioso escuchar el punto de vista de la doctora en cuanto a las causas de los problemas del sistema escolar sueco, pero creo que es importante en el caso chileno que nos basemos no solamente en formular críticas, sino en crear hipótesis y probarlas a través de intervenciones o modelos que se vayan evaluando, ojalá en comparación con hipótesis e intervenciones alternativas. En el ámbito de lenguaje y lectura, la verdad es que se ha ido dejando atrás de a poco la guerra de la lectura (la guerra ideológica de metodologías), especialmente en Estados Unidos, para abrirse más a un consenso basado en la investigación empírica de lo que necesitan nuestros niños y niñas en distintos contextos, como demuestra el consenso del texto clásico de la Academia Nacional de Ciencias de Estados Unidos: Snow, Burns \& Griffin (1998). Ojalá que pudiéramos volver a algunos principios básicos de evaluaciones rigurosas, como que no se debería evaluar a un grupo que ha recibido una intervención sin cotejarlo con algún grupo de referencia o grupo control con niños y niñas comparables para poder mostrar el impacto real de la intervención (Strasser, 2006). Por ejemplo, la reforma de la jornada escolar completa en Chile se implementó en todo el sistema escolar. Hasta la fecha, no tenemos ningún indicio de que haya mejorado el rendimiento de los alumnos y alumnas. El problema es que nunca se pudo contrastar alumnos y alumnas que cambiaron a la jornada escolar completa con un grupo comparable que no se cambió para poder medir el impacto de la reforma. En cambio, un estudio que se ha hecho famoso es el Perry Preschool, que consigna que en Estados Unidos se asignó por un sistema de lotería una intervención muy intensiva a nivel de párvulos a un grupo de niños y 
niñas muy pobres de tres y cuatro años y otro grupo no recibió la intervención; se ha mostrado que el impacto a largo plazo ha sido impresionante: los que participaron en la intervención alcanzaron a estudiar más tiempo en la escuela, tienen menos probabilidades de estar en la cárcel, y muchos otros resultados importantes (Cunha \& Heckman, 2007).

Tenemos que crear una ciencia de cómo llevar las intervenciones exitosas a escala

Es interesante escuchar los estudios de caso que comparte la doctora Enkvist de una escuela exitosa y una menos exitosa en Suecia, pero en este momento en Chile y en todo el mundo necesitamos no solamente mostrar proyectos piloto que funcionan, sino más bien tenemos que comenzar a crear una ciencia de cómo llevar las intervenciones exitosas a escala, que es lo que todavía nos ha costado en países donde no estamos contentos con nuestros resultados educacionales. El primer paso para lograr eso en Chile sería comenzar a recopilar la información de evaluaciones existentes en Chile de modelos educacionales exitosos y estudiar distintas formas de llevarlos a escala — comparar, por ejemplo, llevar un modelo a escala a través del Ministerio de Educación en una región y probar a través de asistencia técnica directa a municipios o escuelas. De esa forma no nos quedaremos en proyectos piloto que funcionan en pocas escuelas sino en modelos que puedan llegar a informar la política pública.

Disminuir los efectos nocivos de la vulnerabilidad social y la pobreza implica esfuerzos intersectoriales ambiciosos

Además, necesitamos una postura interdisciplinaria e intersectorial en cuanto a cómo sacar a los niños y niñas de la pobreza: sacar adelante a un niño o niña es trabajo conjunto de muchos actores. El mal comportamiento de los estudiantes que le preocupa a la doctora Enkvist en las escuelas suecas es justamente el foco que se está poniendo en intervenciones, especialmente en la educación parvularia, en el desarrollo socioemocional. Eso no implica dejar de lado los contenidos y las expectativas altas, sino más bien entender que los aprendiza- 
jes cognitivos tienen una relación estrecha con la interacción social (Meltzoff, Kuhl, Movellan \& Sejnowski, 2009). Un niño o niña que tiene mejores habilidades sociales en general tiende a ser más exitoso académicamente y a evitar la delincuencia, señala la investigación (Shonkoff \& Phillips, 2000). Además, influye mucho la salud de los más pequeños y tiene repercusiones para su productividad y salud a largo plazo (Shonkoff, Boyce \& McEwen, 2009).

Hasta cierto punto, el problema está en el qué: en contenidos rigurosos con metodologías probadas que fomentan procesos de enseñanza-aprendizaje. Pero más allá de eso es el cómo logramos que se implemente bien la enseñanza en todo el sistema educacional, especialmente con los niños y niñas que están en mayor riesgo social.

\section{BibLIOGRAFÍA}

Cunha, F. \& J. Heckman (2007): “The Technology of Skill Formation”. En American Economic Review 97, 31-47.

Eyzaguirre, B. \& L. Fontaine (eds.) (1997): El Futuro en Riesgo. Nuestros Textos Escolares. Santiago, Chile: Centro de Estudios Públicos.

Foorman, B. R. (ed.) (2003): Preventing and Remediating Reading Difficulties: Bringing Science to Scale. Austin, TX: Pro Ed.

Meltzoff, A. N., P. K. Kuhl, J. Movellan \& T. J. Sejnowski (2009): "Foundations for a New Science of Learning”. En Science 325: 284-288.

Raczynski, D. \& G. Muñoz (2007): "Reforma Educacional Chilena: El Difícil Equilibrio entre la Macro y la Micropolítica”. Serie Estudios Socio/Económicos 31: 1-78.

Ramírez, M. J. (2006): "Understanding the Low Mathematics Achievement of Chilean Students: A Cross-National Analysis Using TIMSS Data”. En Journal of Educational Research 45.3: 102-116.

Shonkoff, J. P., W. T. Boyce y B. S. McEwen (2009): “Neuroscience, Molecular Biology, and the Childhood Roots of Health Disparities: Building a New Framework for Health Promotion and Disease Prevention”. En Journal of the American Medical Association 301.21: 2252-2259.

Shonkoff, J. P., y D. A. Phillips (2000): From Neurons to Neighborhoods: The Science of Early Childhood Development. Washington, DC: National Academy Press.

Snow, C. E., M. S. Burns \& P. Griffin (1998): Preventing Reading Difficulties in Young Children. Washington, DC: National Academy Press.

Strasser, K. (2006): "Evaluación de Programas de Intervención Temprana”. Santiago, Chile: Expansiva.

Vygostky, L. S. (1978): Mind in Society: Development of Higher Psychological Processes. Cambridge, MA: Harvard University. 


\section{CONTRA EL "PEDAGOGISMO*}

\section{Arturo Fontaine}

1. Las explicaciones usuales de los problemas de nuestra educación apuntan a la municipalización, el estatuto docente (inamovilidad), las bajas rentas del profesorado, el monto insuficiente del subsidio estatal, la mala estructuración del subsidio (es independiente del logro), el bajo nivel cultural de las familias, la falta de evaluación del profesorado... En estos diagnósticos la falla es sistémica y corresponde rediseñar la institucionalidad. La solución pasa por la política y es tarea del Estado. La profesora Enkvist pone, en cambio, el acento en la formación del profesorado, en el enfoque intelectual predominante en cuanto a cómo educar. Propone un cambio de filosofía educacional, el que debe acarrear consecuencias en cuanto a la formación del profesorado y a su manera de encarar la tarea de educar. Su visión sí tiene implicancias políticas respecto a la selección del profesorado y a sus rentas.

La profesora Enkvist hace una crítica elocuente y apasionada a la escuela de pensamiento educacional que llama "pedagogismo" y a las posturas que directa o indirectamente la alimentan, como el constructivismo, por ejemplo.

La profesora Enkvist se escapa de los enfoques economicistas que ven la educación como un mero instrumento para lograr el crecimiento económico. Ella entiende que el destino de la educación es incorporar a los alumnos a una cultura y la cultura es algo así como nuestro hogar espiritual. Nuestra actividad propiamente humana se juega en la comprensión, construcción, expansión y renovación de una cultura al interior de la cual somos lo que somos y sin la cual nuestras acciones pierden sentido.

Arturo Fontaine. Licenciado en Filosofía, Universidad de Chile. M. A y M. Phil. en Filosofía, Columbia University. Director del Centro de Estudios Públicos, profesor del Departamento de Filosofía de la Universidad de Chile, ensayista y escritor. Autor de las novelas Oír su Voz (reeditada por Alfaguara) y Cuando Éramos Inmortales (Alfaguara) y de los libros de poesía Nueva York (Editorial Universitaria), Poemas Hablados (Francisco Zegers Editor), Tu Nombre en Vano (Editorial Universitaria) y Mis Ojos x tus Ojos (Andrés Bello). 
"Suecia ha llegado a ser un 'país probeta' en cuanto a la educación” (p. 87)1 ${ }^{1}$, afirma Enkvist. El “pedagogismo” y el “constructivismo” se han transformado en la corriente educacional hegemónica. Un caso paradigmático lo constituye "el proyecto de Färila”. Había allí recursos excepcionales y no más de quince alumnos por curso. En esta escuela se eliminaron las clases formales, se entregó a cada alumno un computador portátil y se los incentivó a iniciar una exploración personal de los diversos temas, a construir su propio conocimiento. Debían preparar informes para el profesor para mostrar sus avances. La evaluación de la experiencia ha sido negativa: "en la prueba de lengua final de la escuela obligatoria esta escuela obtuvo resultados sorprendentemente bajos” (p. 88).

Un proyecto opuesto se llevó a cabo en Rinkeby, en las afueras de Estocolmo. Las maestras desarrollaron allí un programa intenso de lecturas de cuentos, practicaron la escritura de relatos, organizaron representaciones, invitaron a una destacada autora de cuentos infantiles. En fin, a los nueve años, tras tres años de este proyecto, muchos alumnos habían leído ya más de 400 libros. "El proyecto Rinkeby sugiere que lo esencial”, afirma Enkvist, "es la buena preparación de las maestras y el trabajo intensivo con los niños". A su juicio, las maestras de esa escuela de Rinkeby "pertenecen a la antigua escuela de maestras que se concentra en la adquisición de la lectoescritura durante los primeros años. La formación de las nuevas maestras está en manos de tendencias psicopedagógicas que privilegian la comprensión de los problemas de los alumnos antes que su progreso intelectual”.

\section{Marco de referencia}

¿Está sola la profesora Inger Enkvist? ¿Se puede decir que su posición carece de respaldo entre los académicos que se dedican a estos asuntos? ¿Es Inger Enkvist una rara avis?

En cierto modo sí. No hay duda de que su posición no es la de la mayoría; no hay duda de que sus posturas son atrevidas, directas, tajantes y desafían al saber establecido y convencional.

${ }^{1}$ Enkvist, Inger: "La Influencia de la Nueva Pedagogía en la Educación: El Ejemplo de Suecia”, 2009. Todas las citas de Inger Enkvist corresponden al mismo ensayo, el que se publica en esta edición de Estudios Públicos. 
Sin embargo, no está completamente sola. Las citas que siguen muestran que no, que hay otros en una línea análoga. De hecho, críticas semejantes a las suyas se están haciendo cada vez más frecuentes ente los especialistas. Es el caso, por ejemplo, de Richard Mayer, que es un experto en la enseñanza multimedial. Es decir, es alguien que está en la frontera de los métodos de enseñanza; quiero decir, no es alguien que se dedique al estudio del latín medieval... Dice Richard Mayer: "La investigación de esta breve revisión muestra que la fórmula constructivismo = actividades prácticas directas es una receta para el desastre educacional [...]. Las actividades pueden promover un aprendizaje que tenga sentido; pero en vez de actividades prácticas per se (esto es, acciones prácticas directas, discusiones y la exploración libre), las actividades que realmente promueven un aprendizaje que tiene sentido son las actividades cognitivas (esto es, seleccionar, organizar, integrar los conocimientos) [...] Los métodos que se fundan en el aprendizaje a través del hacer y en el aprendizaje a través de la discusión deben ser juzgados no según cuánto hacer y cuánta discusión se lleva a cabo sino más bien según el grado en que promuevan un proceso cognitivo apropiado. La dirección, la estructura, y las metas bien enfocadas no debieran ser ignoradas [...] El puro descubrimiento no funcionó en los sesenta, no funcionó en los setenta, no funcionó en los ochenta [...], por lo tanto hay pocas razones para creer que de alguna manera funcionará hoy"2.

La posición de Mayer es categórica: los métodos de enseñanza que, invocando el constructivismo, se basan en el saber hacer y en la discusión deben ser evaluados en función de cuánto aprende el niño, de cuán efectivos realmente son. No sólo eso: no deben reemplazar la dirección, la estructuración del contenido, las metas claras. Si por

2 "The research in this brief review shows", dice Mayer, "that the formula constructivism $=$ hands-on activity is a formula for educacional disaster [...] Activity may help promote meaningful learning; but instead of behavioral activity per se (e.g., hands-on-activity, discussion, and free exploration), the kind of activity that really promotes meaningful learning is cognitive activity (e.g., selecting, organizing, integrating knowledge) [...] Methods that rely on learning by doing or learning by discussion should be judged not on how much doing or discussion is envolved but rather on the degree to which they promote apropiate cognitive processing. Guidance, structure, and focused goals should not be ignored [...] Pure discovery did not work in the 1960s, it did not work in the 1970s, and it did not work in the 1980s, so [...] there is little reason to believe that pure discovery will somehow work today." (Richard E. Mayer, American Psychologist 59, 2004). 
"constructivismo" se entiende actividades prácticas directas (hands-on education) estamos ante una receta que conduce al desastre.

¿Cuál es el error fundamental de esta metodología que muchos asocian al constructivismo, haya sido ésa o no la intención de los padres de dicha filosofía? A juicio de Kirschner, Sweller y Clark la falla consiste en intentar realizar en la clase lo que un investigador hizo al crear o descubrir algo; esto es, un teorema o una ley de la naturaleza. La idea no puede ser más atractiva: que la sala de clases replique lo que fue o podría haber sido el proceso del gran hallazgo, que el alumno por un momento sea Pitágoras o Newton.

Según Kirschner, Sweller y Clark esta cita de Hurd ejemplifica el problema: "La enseñanza de la ciencia [según Hurd] 'debiera ser el reflejo de una disciplina científica tanto en cuanto a su estructura conceptual como a su patrón de investigaciones. Las teorías y métodos de la ciencia moderna debieran reflejarse en la clase' (Hurd, 1969). [...] La mayor falacia de esta racionalización es que no hace distingos entre el comportamiento y los métodos de un investigador que es un experto practicando una profesión y esos estudiantes que son nuevos en la disciplina y que son, por tanto, esencialmente novatos. [...] En tanto y cuanto hay alguna evidencia de estudios controlados, de manera casi uniforme ella apoya, respecto de la instrucción de novatos y alumnos intermedios, una conducción directa y robusta, en lugar de una conducción mínima basada en el constructivismo”3.

Los estudios controlados demuestran, según estos autores, la ineficacia de este proyecto a primera vista tan atractivo. La clase con alumnos novatos e intermedios no debe intentar repetir los métodos y procedimientos con los que se hace la ciencia.

3 “The instruction in science [según Hurd] 'should be mirror image of a science discipline, with regard to both conceptual structure and its pattern of inquiry. The theories and methods of modern science should be reflected in the classroom' (Hurd, 1969) [...]. The major fallacy of this rationale [siguen diciendo Kirschner, Sweller y Clark] is that it makes no distinction between the behavior and methods of a researcher who is an expert practicing a profession and those students who are new to the discipline and who are, thus, essentially novices. [...] In so far as there is any evidence from controlled studies, it almost uniformly supports direct, strong instructional guidance rather than constructivist-based minimal guidance during instruction of novices to intermediate learners". (Paul A. Kirschner, John Sweller and Richard E. Clark, Educational Psychologist, 2006.) 
¿Por qué las clases son difíciles y, casi siempre, más aburridas que salir al patio a jugar? ¿Por qué las clases no pueden ser lugares de juego? ¿ No habrá una manera de aprender que sea tan entretenida y amena como jugar? Muchos maestros hoy se empeñan en hacer clases que diviertan a los alumnos y sienten que su deber es competir con los juegos y entretenciones a los que ellos se entregan con entusiasmo y espontaneidad.

Algunos psicólogos evolutivos creen que hay una diferencia significativa entre la adquisición de habilidades primarias — tales como hablar, caminar, sonreír, interpretar los gestos de una cara- y la adquisición de habilidades secundarias — tales como la lectura, el álgebra o la física-. Las primeras se expresan como impulsos espontáneos que provienen directamente de la forma en que evolucionó nuestra constitución biológica. Las segundas, en cambio, son el resultado de la invención humana y no surgen en nosotros con la natural facilidad con que brotan las primeras. Esto a pesar de que interpretar un rostro es probablemente más complejo que leer. Lo primero nos sale solo. Leer, no. Las habilidades y conocimientos primarios se logran a través de conductas como el juego o la conversación en la que hay una alegría natural. En cambio, las habilidades y conocimientos secundarios, sostiene Geary, se adquieren a través del trabajo y el esfuerzo. ¿Hay espacio para una pedagogía lúdica? Sí, pero es limitado. Un juego matemático o científico puede, en ciertos casos, agilizar la enseñanza, pero difícilmente puede rivalizar con un juego diseñado sólo para divertir. Y hay áreas importantes del conocimiento que un alumno novato o intermedio corriente no aprenderá jugando o divirtiéndose, sino que a través de un esfuerzo paciente.

Según Geary: “[L]a motivación para adquirir habilidades secundarias que se enseñan en la escuela procede de la sociedad mayor y no de los intereses intrínsecos de los niños. [...] Los niños innatamente buscan experiencias, por ejemplo a través de los juegos con otros niños, que conducen al desarrollo de estos sistemas primarios. En cambio, no hay una estructura innata que sostenga la adquisición de actividades secundarias, la gran mayoría de los niños no está inherentemente motivados como para comprometerse en las actividades que son necesarias para la adquisición del aprendizaje secundario. Aunque esta conclusión parezca evidente, va en contra de muchos de los supuestos acerca del aprendizaje de los niños en la educación contemporánea. 
[...] Instruir implica comprometer a los niños en actividades que facilitan la adquisición de habilidades secundarias, estén o no estén los niños inherentemente interesados en esas actividades. Esto no significa que el juego y actividades sociales no puedan usarse para comprometer a los alumnos en algunos aspectos de las áreas secundarias del conocimiento. No obstante, sí significa que es muy improbable que el dominio de muchas áreas de conocimiento secundarias (esto es, la lectura o el álgebra) se consiga sólo con ese tipo de actividades primarias. [...] En algunas áreas, tales como las ciencias biológicas y físicas, el dominio de ellas va a requerir también muchas acciones prácticas directas, como el llevar a cabo experimentos, sin embargo también se necesitarán métodos más tradicionales (esto es, aprender hechos fundamentales y principios, como la teoría de la evolución)”4.

Según Geary y Hamson, no cabe esperar que los alumnos se sientan atraídos espontáneamente por el álgebra o la física de la manera en que se sienten atraídos por hacer amigos y jugar y disfrutar con ellos. Geary y Hamson creen que el notorio fracaso de los Estados Unidos en las pruebas internacionales de matemáticas y ciencias se debe a que buena parte de sus profesores han sido enseñados en esta idea alegre. Algo similar, me parece, ocurre en Chile, donde diversas variantes del constructivismo predominan en las escuelas de pedagogía. (Estados Unidos, pese a sus recursos, logra en la prueba PISA de matemáticas resultados similares a los de España. España es el número 29 y Estados Unidos el número 31.) En los países asiáticos, cuyos

4 “[T]he motivation to acquire school-taught secondary habilities is based on the requirements of the larger society and not on the inherent interest of children [...] Children are inherently motivated to seek out experiences, for example, through social play, that ensure the development of these primary systems. In contrast, there is no inherent structure supporting the acquisition of secondary habilities, nor are most children inherently motivated to engage in the activities that are necessary for secondary learning. While this conclusion might seem self evident, it runs counter to many assumptions about childrens learning in contemporary education [...] Instruction must therefore involve engaging children in activities that facilitate the acquisition of secondary abilities, whether or not children are inherently interested in engaging in these activities. This does not mean that play and social activities cannot be used to engage in some forms of secondary domains. It does, however, mean that it is very unlikely that the mastery of many secondary domains (e.g., reading or algebra) will occur with only these types of primary activities. [...] For some domains, such as biological and physical sciences, mastery will also require many "hands on" activities, as in conducting experiments, although more traditional methods will be needed as well (e.g., learning basic facts and principles, such as the theory of evolution)." (David C. Geary, "Evolutionary Theory and Education”, 2001.) 
resultados son excelentes, se practica una pedagogía basada en el esfuerzo constante, el avance gradual y estructurado, la ejercitación sistemática y la conducción del profesor según textos de estudio que abordan claramente el contenido que los alumnos deben aprender.

David C. Geary y Carmen O. Hamson: "[L]a curiosidad acerca de las intenciones de los demás y el deseo de establecer relaciones con la gente parecen ser un objetivo natural y casi universal. Un quemante deseo de dominar el álgebra o la física newtoniana no es algo que sea tan universal. [...] La motivación para aprender es necesaria pero de hecho no producirá por sí sola competencias académicas en matemáticas y ciencias. La adquisición de competencias matemáticas y de las vinculadas a las ciencias requiere comprometerse en actividades que estén específicamente diseñadas para fomentar su desarrollo"5.

Ni el modelo del descubrimiento científico ni el del juego deben inspirar, en general, la enseñanza de alumnos novatos e intermedios. Steven Pinker estima que la escuela constructivista ejemplifica el supuesto de que la mente humana es una tábula rasa y carece, por tanto, de características innatas o inherentes que fueran seleccionadas por la evolución: "En la filosofía de la enseñanza de las matemáticas conocida como constructivismo, a los niños no se les adiestra en las tablas de multiplicar sino que se les prescribe que ellos mismos deben redescubrir las verdades matemáticas resolviendo problemas en grupo. [...] Entender la mente como un sistema complejo configurado por la evolución va en contra de estas filosofías. [...] Educar no es ni escribir en una tábula rasa ni es permitir que florezca la nobleza del niño. Más bien, la educación es una tecnología que intenta subsanar aquello para lo cual la mente humana es innatamente mala"6.

5 “[...] curiosity about other people intentions and the desire to seek out relationships with other people appears to be a natural and near universal goal. A burning desire to master algebra or Newtonian physics is not so universal [...] Motivation to learn is necessary but will not and of itself actually produce academic competences in mathematics and sciences. The acquisition of mathematical and science-related competences requires engaging in activities that are specifically designed to foster their development.” (David C. Geary and Carmen O. Hamson, Education Directory, 2009).

6 "In the philosophy of mathematics instruction known as constructivism, children are not drilled with arithmetic tables but are enjoined to rediscover mathematical truths themselves by solving problems in groups [...] An understanding of the mind as a complex system shaped by evolution runs against these philosophies. [...] Education is neither writing in a blank slate nor allowing the child's nobility to come into flower. Rather, education is a technology that tries to make up for what the human mind is innately bad at.” (Steven Pinker, The Blank Slate, 2002.) 
Pinker también enfatiza, entonces, la educación como un proceso arduo que requiere rigor.

La pedagogía de raíz constructivista a menudo pone el acento en la educación a base de proyectos. La idea es que no sea el profesor o el texto de estudio la fuente de un saber impuesto desde arriba, sino que, más bien, el alumno investigue y salga a buscar el conocimiento. Un alumno activo encuentra el conocimiento en enciclopedias y libros de la biblioteca, en experimentos, en internet. Los contenidos se exponen a los compañeros de clase por parte de sus pares. La enseñanza es más horizontal que vertical. El concepto es atrayente y, de nuevo, en ciertas áreas y bajo la guía de un profesor adecuado, puede emplearse con eficacia. Sin embargo, es lento. Con frecuencia estos proyectos se hacen en grupo y los diferentes miembros del grupo trabajan de modo muy desigual, lo que hace injusta una nota común. No es fácil averiguar, por otra parte, quién hizo qué sin destruir la obra en común. Pero, aparte de ello, los proyectos se hacen con apoyo de material bibliográfico y audiovisual que cada alumno busca. Los hermanos mayores y los padres con frecuencia ayudan a encontrar dichos materiales y orientan la labor del niño.

El método tiene un efecto no buscado: la inequidad. Es obvio que un niño cuya madre es médico podrá "encontrar" los materiales escritos y audiovisuales que le permitirán entender y exponer ante su curso qué es el sistema linfático y qué funciones cumple. La madre que terminó apenas octavo básico no tiene en casa dichos materiales ni está en condiciones de ayudar a su hijo en ese proyecto. Como resultado, el curso no recibirá una explicación sobre el sistema linfático comparable a la que recibirán los compañeros del hijo de la doctora. Mientras más descansa el método en contenidos que el niño debe salir a buscar, más son las ventajas para los alumnos de hogares cultos y acomodados.

"Una de mis objeciones”, escribe Hirsh, "a la pedagogía naturalista y romántica es su grave ineficiencia. La enseñanza ineficiente determina que lo que se aprende fuera de la escuela adquiera más importancia relativa que lo que se aprende dentro de ella. Tal es el estado de cosas en Estados Unidos, según lo demuestra el informe Coleman. Es la fórmula perfecta para perpetuar la injusticia social.” “[...] Tómese como ejemplo aquel icono de la pedagogía romántica, el 
método de proyectos, que se conoce también como aprender en la práctica o aprendizaje temático. Éste es hoy el método preferido en los institutos pedagógicos de Estados Unidos para enseñar todas las materias, hasta las matemáticas. No voy a dedicar tiempo a explicar por qué este método llamado 'naturalista' o 'del mundo real' ha alcanzado una popularidad tan grande. Para muchos niños resulta entretenido, sin duda. Incluso habría cierta justificación teórica para usarlo de vez en cuando. Pero como método de enseñanza es no sólo ineficiente sino doblemente injusto. En primer lugar, como ocupa demasiado tiempo en enseñar demasiado poco, automáticamente ensancha la brecha de aprendizaje entre los que pueden aprender mucho fuera de la escuela y los que aprenden principalmente dentro de la escuela. Es injusto, además, porque es un método que tiene éxito con ciertos alumnos, pero no con todos. Y los que quedan fuera son, con excesiva frecuencia, niños de hogares desfavorecidos.” (E. D. Hirsch, Estudios Públicos, 1999.)

Si los contenidos no se aprenden del profesor ni del texto de estudio se aprenderán, si es que se aprenden, en la casa. Si lo que se enseña refleja los conocimientos de los hogares es claro que la educación no logra su propósito. Los niños que vienen de hogares cultos tienen una ventaja inevitable. Mientras exista la institución de la familia esto va a ser así. Pero la pregunta es si hay pedagogías que multiplican la importancia relativa de la cuna. Y parece que las hay. Son las que se emplean profusamente en países como Estados Unidos, Chile y Suecia, como nos explica la profesora Inger Enkvist. No, en cambio, en Finlandia, que en las pruebas PISA destaca como el mejor país del mundo en la enseñanza de las matemáticas y de las ciencias, y el segundo en lenguaje.

\section{Inger Enkvist: Párrafos marcados}

En pocas páginas, Inger Enkvist aborda muchos de los problemas que nos preocupan. Su visión es crítica del "pedagogismo" en sus diversas modulaciones. Desde luego, se hace cargo de la cuestión de la disciplina:

El problema es que si la escuela es tolerante con el mal comportamiento no logrará imponer conductas positivas. Lejos de disminuir el número de alumnos con problemas graves, el 'buenismo' hace que éstos aumenten (p. 92). 
Según Enkvist, el "pedagogismo” reduce la evaluación. La propia metodología favorecida trae consigo una reformulación de la evaluación: en lugar de resultados se tiende a premiar la autoexpresión.

Desaparece cada vez más la evaluación de resultados para que no se haga obvio que algunos avanzan más que otros. En vez de pedir al alumno que no ha aprendido que repita, se instala la promoción automática. [...] Se introduce el proyecto como forma de trabajo y la metodología del proyecto requiere que el alumno elija libremente el tema y una manera de trabajar [...] Así es como los trabajos de los estudiantes empiezan a ser considerados como la expresión de la personalidad del alumno [...] La idea de fondo es que todo trabajo tiene algún valor y que no se puede distinguir entre una categoría de esfuerzo y otra, y así desaparece cualquier distinción entre quien hizo esfuerzos y quien no (p. 94).

Hay miedo a la selección y, en general, a la meritocracia. En los deportes se selecciona sin temor $\mathrm{y}$, en cuanto se puede, se hace jugar a los alumnos en contra de otros de nivel similar. No hay temor a los traumas que pudiera ocasionar no ser seleccionado para representar al colegio o no quedar en el primer equipo. No hay aquí mucha confianza en la capacidad de los buenos jugadores de contagiar a los malos. En cambio, en las actividades académicas, como la enseñanza de las lenguas o de las matemáticas, los criterios cambian. ¿Por qué?

"Se cree”, afirma Enkvist, "en el contagio de la inteligencia en el sentido de que si estudian juntos los inteligentes y los menos inteligentes, éstos se desarrollarán más rápido. [...] La teoría expresa pesimismo pedagógico porque considera imposible que un alumno proveniente de un medio intelectualmente pobre logre buenos resultados por su propio esfuerzo" (p. 95).

Se redefine la tarea del profesor: ahora es un "facilitador". Como ya se dijo, no debe impartir conocimientos sino ayudar a que los alumnos los hallen. Se supone que el proceso es más educativo que el resultado, así el alumno aprenderá a aprender.

"El nuevo papel del docente es, al contrario, el de un facilitador, alguien a quien se puede consultar. [...] En vez de concentrarse en la adquisición de conocimientos básicos, ahora despectivamente llamados escolares o formales, el alumno debe aprender técnicas para manejar 
un computador, encontrar información y presentarla. [...] El constructivismo da prioridad al cómo sobre el qué. Así el método usurpa el sitio de los saberes tradicionales” (p. 99).

A menudo cuando alguien hace críticas al constructivismo la respuesta defensiva es que lo que se está criticando no es propiamente el constructivismo, que está mal aplicado, que se lo ha llevado a un extremo, que la intención era otra, que el constructivismo adopta diversas modalidades, que ha sido mal comprendido [...] Pero lo que Enkvist objeta —el profesor no como conductor de un proceso de aprendizaje de determinados contenidos sino como "facilitador" - es el punto medular. Lo demás es una discusión escolástica.

La escuela no debe ser meritocrática ni exigir rigor. Más bien se la concibe como un espacio de socialización lo más espontáneo y lúdico posible, sigue argumentando Enkvist. Se quisiera evitar que el profesor establezca prioridades, exigencias, jerarquías y exclusiones.

"El pedagogismo se opone a toda selección [...] Los pedagogistas exigen que la escuela se abra a la vida, por ejemplo, a través de excursiones, visitas y trabajos prácticos que sustituyen al trabajo libresco. [...] La escuela se ha cerrado cada vez más al esfuerzo prolongado, la exigencia, el entusiasmo por el estudio, la puntualidad y la pulcritud. Ha dejado entrar lo trivial como el mundo de la televisión, y ha salido la cultura. Estar matriculado ya no significa estudiar, sino que la escuela también ha pasado a ser parte de la excitación y diversión. Ahora la idea de que el aprendizaje debe ser divertido ha calado en la población [...]” (pp. 101-102).

La pobreza de los conocimientos daña la capacidad crítica de los alumnos:

"En cuanto al fracaso escolar los pedagogistas lo consideran como casi automático para los alumnos de bajo estrato socioeconómico. [...] El resultado [...] es que los alumnos son moralistas pero no críticos. Para ser crítico, hay que conocer el campo en cuestión. Para tener una opinión sobre la guerra de la ex Yugoeslavia, hay que saber algo de la ex Yugoeslavia. [...] Lo históricamente nuevo es que tenemos deserción escolar dentro de la escuela” (p. 102).

"[L]o moderno se presenta como todo vale. Cualquier opinión vale lo mismo que las conclusiones de alguien que ha estudiado un campo de conocimientos. En vez de dar énfasis al aprendizaje se desculpabiliza a la ignorancia” (p. 104). 
La lectura se mira como algo meramente utilitario. Por tanto, leer una receta de cocina vale lo mismo que leer una página de Cervantes o de Neruda. Con la ventaja de que quien lee una receta acerca de cómo preparar una pizza después puede hacer una. La comprensión de lectura se comprueba en la práctica...

"Los nuevos psicopedagogos", escribe Enkvist, "sugieren que la lectura se considere como algo puramente instrumental, por lo que es lo mismo leer publicidad o fragmentos de periódicos que textos literarios. Lo mismo es leer algo escrito por un compañero de clase que una obra literaria maestra” (p. 104).

Con todo, se están abriendo otros caminos. La profesora Enkvist se interesa por el informe McKinsey que trata de averiguar qué explica los resultados de los países a los que les va bien en las pruebas PISA.

"La novedad del informe [informe McKinsey] es que subraya que hay que ocuparse en primer lugar de lo esencial y que lo esencial es la calidad del profesor” (p. 111).

Y ¿qué hacen los países exitosos? “(1) Eligen a sus futuros profesores entre los mejores alumnos que salen del bachillerato. (2) Para poder hacerlo, les pagan tanto como se les paga a otros profesionales de alto nivel. (3) Los educan con los mejores profesores universitarios. [...] (5) Les hacen un seguimiento durante los primeros años de ejercicio de la profesión” (p. 111).

Por su parte los finlandeses, sostiene Enkvist, "atribuyen sus buenos resultados a los siguientes factores: maestros y profesores con buena preparación académica; madres con una alto nivel educacional que ayudan a sus hijos en las tareas; familias que apoyan a los docentes; un sistema escolar con metas claras; inversión del Estado en educación; y grupos de aprendizaje no muy numerosos. Se podría añadir: Finlandia no ha introducido la nueva y problemática pedagogía” (pp. 112-113).

4. En el fondo, el viejo tema del "buen salvaje"

¿Cuál es el trasfondo del ideal de este conjunto de ideas, aspiraciones y proyectos que anima al educador imbuido en lo que Enkvist llama “pedagogismo” y “nueva pedagogía”? Es un antiguo mito, arrai- 
gado y, casi siempre, no consciente: es el mito del buen salvaje. Para el romanticismo temprano, el de Rousseau, entre otros, los niños y los campesinos eran buenos porque eran más inocentes, estaban más cerca del buen salvaje que el adulto, corrompido por la civilización. Ese gran educador francés que fue Émile Chartier, que firmaba como "Alain”, no ve a los niños como buenos salvajes sino todo lo contrario:

El niño está en el estado salvaje. Esto ha llevado a la desesperación a más de un hombre estimable, dedicado, afectuoso. [...] El orden que hay que establecer en esta sociedad no debe parecerse en absoluto al orden familiar ${ }^{7}$.

Diderot, en su célebre Supplément au Voyage de Bouganville, hace hablar de esta manera a un viejo tahitiano. El hombre se dirige a Bouganville en ánimo de reproche. El navegante europeo y su civilización destruirán una sociedad feliz e inocente: "Somos inocentes, somos felices, y tú no puedes sino destruir nuestra felicidad. Nosotros seguimos el puro instinto de la naturaleza, y tú has intentado borrar de nuestras almas su carácter" 8 .

A veces siento que los profesores están inseguros. Los han cohibido los expertos de la psicología cognitiva, de la sociología de la educación, de las teorías constructivistas. Quisiera darles un mensaje de confianza. Ustedes conocen a sus alumnos, ustedes saben mejor que nadie cuánto pueden aprender. Cito a Alain, quien no pudo decirlo mejor:

Usted dice que hay que conocer al niño para instruirlo; pero esto no es en absoluto verdadero; yo diría, más bien, que hay que instruirlo para conocerlo; pues su verdadera naturaleza es su naturaleza desarrollada por el estudio de las lenguas, los autores y las ciencias. Es enseñándole a cantar que sabré si es músico ${ }^{9}$.

7 "L'enfant est à l'état sauvage. Cela a réduit au désespoir plus d'un homme estimable, dévoué, affecteux. [...] L’ordre que doit s'établir en cette société ne doit ressembler nullement à l'ordre familial.” Alain, Propos sur l'Education, 1932.

8 "Nous sommes innocents, nous sommes heureux, et tu ne peux que nuir à notre bonheur. Nous suivons le pur instinct de la nature, et tu as tenté de d'effacer de nos ames son caractère.” (Denis Diderot, Supplément au Voyage de Bouganville.)

9 "Vous dites qu'il faut connaitre l'enfant pour l'instruire; mais ce ne point vrai; je dirais plutôt qu'il faut l'instruire pour le connaitre; car sa vraie nature c'est sa nature développé par l'étude des langues, des auteurs et des sciences. C'est en le formant à chanter que je saurais s'il est musicien.” Alain, Propos sur l'Education, 1932. 


\section{REFERENCIAS}

Alain (Émile-Auguste Chartier): Propos sur l'Eduaction. Presses Universitaries de France, 1986.

Diderot, Denis: Supplément au Voyage de Bouganville [1772].

Enkvist, Inger: "La Influencia de la Nueva Pedagogía en la Educación: El Ejemplo de Suecia”. En Estudios Públicos, 115, 2009.

Geary, David C.: “Evolutionary Theory and Education”. En N.J. Smelser y P. B. Baltes (ed.), International Enciclopedia of Social \& Behavioral Sciences, 2001.

Geary, David C. y Carmen O. Hamson: "Improving the Mathematics and Science Achievement of American Children: Psychology’s Role”. En Education Directory, American Psychological Association 2009. http:/www.apa.org/ed/ geary.hotmail.

Hirsh, E. D.: "Equidad y Excelencia: Metas Alcanzables en Educación”. En Estudios Públicos 73 (1999).

Kirschner, Paul A., John Sweller y Richard E. Clark: "Why Minimal Guidance during Instruction Does Not Work: An Analysis of the Failure of Constructivist, Discovery, Problem-Based, Experiential, and Inquiry-Based Teaching”. En Educational Psychologist Vol. 41: 2 (2006).

Mayer, Richard: "Should There Be a Three Strikes Rule against Pure Discovery? The Case for Guided Methods of Instruction”. En American Psychologist 59: 1 (2004).

Pinker, Steven: The Blank Slate. The Modern Denial of Human Nature. Londres: Allen Lane, 2002. 
RESPUESTA A LOS COMENTARIOS DE LOS PANELISTAS*

\section{Inger Enkvist}

Lo primero sería un comentario a propósito de la igualdad. Mi punto de vista es que el sistema era más igualitario en Suecia antes de que comenzaran las reformas. En ese entonces el sistema tenía a la vez más calidad y era más igualitario, más equitativo, si se quiere decir. Lo mismo ocurre con Finlandia, que ha logrado la más alta calidad del mundo y mantiene a sus alumnos en el colegio más tiempo que los suecos. Hay menos drop outs [deserción escolar] en Finlandia que en Suecia, las exigencias son más altas y los resultados mejores. Claramente las exigencias no generan desigualdad, sino que al revés, son las exigencias las que permiten que los alumnos de familias no tan avanzadas culturalmente surjan también, para el bien suyo y el de la sociedad. $\mathrm{Y}$ por eso es que vemos que Finlandia avanza, avanza, avanza, sin vuelta atrás. En el pasado Finlandia era más pobre que Suecia y menos igualitario en la educación: eso es avanzar.

Los países del sureste asiático están avanzando, avanzando y después de PISA muchos países han empezado a trabajar. Hace poco estuve en Estonia y se ve como están trabajando y avanzando mucho. No hay vuelta atrás, se va hacia adelante...

Otro comentario: ¿cómo lograr calidad y equidad a la vez? Teniendo un programa o currículum sistemático, con cosas que se aprenden el primer año, el segundo año, el tercer año... y estar seguros de que esto se cumpla, dándoles a todos los alumnos los mejores profesores posibles y un programa claro. Al llegar a los 13 o 14 años, se debe mantener la escuela obligatoria, pero ofreciendo algunas opciones 0 itinerarios, porque entonces los estudiantes son bastante diferentes entre sí, y alguna diversidad en los itinerarios puede ayudarlos a encontrar interés en lo que están haciendo,

A propósito de sociología y pedagogía, voy a provocar otra vez. Mi punto de vista fundamental es que los sociólogos de la educación, y también una parte de los pedagogos profesionales, aquellos pedagogos

* Transcripción de la respuesta de Inger Enkvist a los comentarios de los panelistas Diego Ibáñez, Francisco Claro, Cristián Cox, Andrea Rolla y Arturo Fontaine tras su exposición "La Influencia de la Nueva Pedagogía en la Educación: El Ejemplo de Suecia”, que se reproduce supra, en esta edición. 
puros que no tienen especialidad en ninguna materia, consumen una parte importante de los recursos destinados a la educación en términos de dinero, puestos e incluso absorben una cantidad considerable del tiempo de los futuros profesores. Mucho del tiempo de la formación continua se canaliza hacia la sociología y la pedagogía teórica, cuando en realidad lo que hace falta es que los profesores aprendan más de sus materias. No quiero decir que la sociología y la pedagogía pura sean absolutamente inútiles, quiero decir que algo del dinero destinado a ellas se debiera dirigir hacia otros campos donde sería más útil aun, eso es lo importante.

Para tener calidad de verdad, los profesores necesitan una mejor base cuando empiezan a enseñar y después necesitan seguir estudiando para mantener el entusiasmo por su materia. Eso lo veo, por ejemplo, con los profesores que asisten a cursos de formación continua: muchos empiezan a sonreír y les brillan los ojos, porque encuentran tanto placer en la materia, en ese mundo que van conociendo y que les gusta enseñar.

Un comentario, entre los muchos que se podrían hacer, se refiere a los Estados Unidos. En el mes de febrero pasé dos semanas en la Universidad de Berkeley, en California, y estudié un poco los rasgos de la educación en California. Como sabemos todos los que leemos el periódico, los californianos tienen un problema de presupuesto en estos momentos y están muy preocupados. Ahora, si se mira lo que ha sucedido allí en los últimos veinte años, nos encontramos con una gran fuente de investigación básica en pedagogía, porque, por casualidad, la situación de integración cultural que ahí se observa nos permite ilustrar cuatro maneras en que se comportan los estudiantes, y esto sí que es provocación. En California se pueden distinguir los grupos de los alumnos asiáticos, los alumnos anglos (blancos de origen europeo), los alumnos afroamericanos y los alumnos hispánicos. Podemos por tanto preguntarnos: ¿Qué actitud tienen? ¿Cómo trabajan? ¿Cómo se mueven en el mundo de la educación?

Los hispánicos, en California, son de origen centroamericano, y muchas veces de origen indígena, al menos en parte. Muchos de ellos tienen problemas de inmigración, legal o no legal, y trabajan temporalmente en la cosecha de fruta y todo eso que sabemos.

Pero ahora no vamos a hablar de los padres, sino que vamos a hablar del comportamiento de los alumnos hispánicos en el mundo de la educación y hablaremos también de cómo piensan. Dicen varios inves- 
tigadores que ellos piensan que el éxito en los estudios es cosa de suerte, que es cosa de tener algo innato y de que se te den las cosas bien. Piensan que se trata de tener al profesor de tu lado. Así es que adjudican el éxito a cosas fuera de ellos mismos, no al esfuerzo.

¿Qué hacen? Dos cosas son llamativas: primero, estudian muy poco en sus casas. Cuando digo "estudian” eso es una generalización (son grupos muy grandes, hay investigaciones con diez mil estudiantes, etc.), estudian poco en su casa en promedio.

Además, se cambian mucho de escuela, por varias razones, algunas de las cuales tienen que ver con la situación de los padres, pero también porque no están a gusto en un colegio, porque tienen amigos en otro colegio, etc.

Hay colegios, al parecer, en el centro de Los Angeles, en que entre el $40 \%$ y $50 \%$ de los alumnos cambia cada año. Como profesora se me "ponen los pelos de punta". Si empiezo con un grupo y un mes más tarde el grupo ha cambiado, y dos meses más tarde se han ido algunos y han venido otros, se hace imposible, absolutamente imposible obtener un buen resultado de esa manera.

El grupo afroamericano es bastante similar, pero obtienen mejores resultados académicos que los hispanos.

Después llegamos a los anglos, y ahí el gran problema es el tiempo que dedican a los estudios, o mejor dicho el tiempo que "no" dedican a los estudios. Una investigadora calcula que éstos realizan unas siete horas de actividades académicas en un día normal de colegio. $\mathrm{Y}$ ¿qué hacen el resto del tiempo? Ella les asigna siete horas para dormir, cada noche, veinticinco horas para transporte, higiene y otras necesidades de subsistencia, por semana. Pero después llegamos a lo interesante: la investigadora habla de entre quince o veinte horas de trabajo, cada semana, por ejemplo en una hamburguesería, para ganar dinero y poderlo gastar durante los fines de semana. Y eso está bastante bien visto: de hecho permite poner en la solicitud para entrar al college: "yo he trabajado" y eso se valora como experiencia laboral.

Además, los anglos realizan variadas actividades extracurriculares, que pueden ser deporte o música. Claro, son actividades divertidas, te desarrollan como persona, y lo pones en la solicitud para que te admitan en un college. Ahí “desaparecen” entre diez y quince horas más.

Después viene un ítem interesante: “actos sociales”. Estas actividades incluyen hablar por teléfono, chatear por internet, quedarse en el 
patio de la escuela hablando con los amigos, yendo a una cafetería, yendo a fiestas de fin de semana, etc. En eso se gastan veinte o veinticinco horas por semana, que es casi tanto como las horas que estos jóvenes pasan en el colegio.

Finalmente, los anglos dedican un total de cinco horas por semana para estudiar en su casa.

Así, es imposible que estos alumnos logren mejores resultados, si la cuestión es si estudian o no estudian. Esto es en serio y lo denuncia todo el mundo. Muchos dicen que la situación no puede seguir así, que es un despilfarro. Se critica que el Estado pague una educación y no se preocupe después de hacer respetar esa educación por parte de los padres y los estudiantes.

En general estos estudiantes piensan que sería bueno sacar buenos resultados ya que "si saco malos resultados, mi mamá se disgustará”. Y ¿qué hacen? Trabajan un poco, no mucho.

¿Cómo piensan los afroamericanos a propósito de eso de fracasar? Dicen que no es deseable, desde luego, pero dicen que tampoco es muy importante, porque ellos conocen casos de estrellas del deporte y de la música que no terminaron la secundaria, y les ha ido muy bien en la vida. Así es que no consideran que el fracaso sea un problema demasiado serio.

Y ahora llegamos al último grupo: a los asiáticos. A este grupo les va estupendamente en California, les va muy, muy bien. Los asiáticos de antes eran japoneses, quizás los nuevos —los recién llegadossean coreanos o chinos. Quizás vietnamitas, por ejemplo.

Primero, ¿cómo piensan estos asiáticos? Piensan que sería un desastre no ser el mejor del grupo, eso simplemente no lo quieren ni imaginar. Así es que esto del fracaso está excluido. Así es como piensan.

¿Cómo piensa en este caso la familia?

Parece que los estudios de los alumnos es el proyecto más importante para la familia de origen asiático. Han emigrado para que sus hijos tengan un mejor futuro. Entonces, la educación de los hijos es el proyecto de todos, y todos ayudan. Hay un sacrificio por parte de la familia, y si se necesita más dinero, no trabaja el alumno, sino que trabaja el padre o la madre.

Y, como es sabido, hasta pagan clases particulares para ayudar a mejorar el desempeño del hijo. Si resultó que al niño le tocó un mal 
profesor de química, la familia le pone un profesor extra para que saque buenas notas en la materia. Así, las familias colaboran con el buen resultado de la escuela. Así es como piensan los asiáticos. Entonces, los hijos estudian cuatro o cinco horas por tarde, casi tanto como un anglo estudia durante toda la semana. Por otro lado, los hispánicos y afros apenas abren el libro.

¿Dónde nos lleva todo esto? Todo esto nos lleva a la conclusión —que otra vez es una generalización basada en un número muy importante de entrevistas - de que el esfuerzo, el respeto por la educación, la esperanza y el esfuerzo, dan resultados.

Y esos resultados no están completamente determinados por el nivel socioeconómico: unos padres chinos muy pobres que sueñan con un hijo doctor constituyen un ambiente estupendo para su hijo.

La explicación del buen desempeño no está determinada directamente por el nivel económico. De hecho, en general los anglos tienen mejor nivel económico, y sin embargo los padres a veces tienen dificultades para estimular a sus hijos para que estudien, porque lo tienen todo. No ven ninguna urgencia para desistir de sus placeres para estudiar y obtener algo que les parece que ya tienen.

Hay una relación estadística entre desempeño y recursos, es verdad, pero no es una ley natural. Si la escuela se presenta, ante los alumnos y los padres de familia, como algo serio e importante para el bien del alumno, se logra la colaboración y el desempeño aumenta. Pero si el alumno no colabora, éste no aprenderá.

Para que no haya malos entendidos, aquí no estamos hablando de grupos étnicos, estamos hablando de actitudes ante la educación. Y, muy importante, tampoco es la lengua de la casa la que aquí determina los desempeños. Si fuera la lengua de la casa, les iría mejor a los anglos y a los afroamericanos, y les iría igual de bien o mal a los asiáticos, como a los hispánicos, y no es así. Si la explicación estuviera en la facilidad de la lengua en comparación con el inglés, les iría mejor a los hispánicos que a los asiáticos.

Tampoco la explicación está en la educación bilingüe asociada —en California sobre todo- a los hispánicos. De hecho, a este grupo le va peor que a los asiáticos que no piden enseñanza de chino en el colegio. Así es que circula una masa de ideas como supuestas "leyes" en educación: "hay que investigar”, "hay que mirar de cerca”, que son 
clichés que hemos aceptado y —para mí- no representan más que una vuelta atrás.

El respeto por la educación, por la cultura, por la manera de convivir, y la convivencia entre alumno y profesor, durante quizás nueve o doce años, en los niveles preuniversitarios, es fundamental. Esta etapa representa una gran parte de la vida. Ese respeto tiene un valor en sí, y nos da un modelo de cómo comportarnos los unos frente a los otros para el resto de nuestra vida. 


\section{DIÁLOGO DE INGER ENKVIST CON EL PÚBLICO}

\section{P.: Quisiera tomar la palabra, en apoyo de la profesora Enkvist.}

Hay algunos aspectos que quisiera añadir. Un panelista preguntó si realmente mucha gente en Suecia compartía las opiniones de la profesora Enkvist, y yo puedo afirmar que sí.

Al menos todos los padres y profesores con los que yo he hablado piensan de esta forma y estamos bastante tristes y decepcionados con los resultados del sistema educacional sueco. Y eso que muchos de nosotros compartíamos inicialmente las ideas básicas de las reformas. $Y$ ahí voy a un aspecto que no se ha tocado todavía, o no mucho, y es que la culpa siempre la tiene alguien y hoy se culpa a la socialdemocracia, porque cuando se hace la primera reforma, la de 1969, gobernaba la socialdemocracia.

Sin embargo, las ideas socialdemócratas sobre la educación no eran ésas, eran otras. El objetivo era elevar la clase obrera al nivel al que todos deberíamos poder aspirar. Pero los resultados han sido nulos.

El Primer Ministro Persson me dijo una vez: "Lo único importante es dedicarse al 10\% de los peores alumnos. Los mejores alumnos, se las arreglan... ". Y no es verdad. Porque si bien en la primera mitad del siglo XX una proporción creciente de jóvenes de hogares obreros llegaron hasta la universidad, en la segunda mitad del siglo XX esa proporción ya no seguía creciendo, se ha mantenido estática. Al mismo tiempo, la calidad y los conocimientos de los que sí han llegado a la universidad - que generalmente son gente de clase media para arriba- se han deteriorado tremendamente. Y ése también es un tema que toca la profesora Enkvist, y tiene toda la razón en sus opiniones.

Creo que de alguna forma sí está el componente ideológico en términos de esta búsqueda de igualdad. Por lo demás se ha probado que por muy igual que sea la educación que reciben los niños, dependiendo de la familia y su origen, éstos van a entender las cosas de forma distinta, y generalmente eso suele reproducir los órdenes sociales.

Adhiero a la tesis de que "la tierra es plana", de Thomas Friedman, porque eso significa que se han igualado, para muchos, las condiciones para desarrollar lo que uno quiera. $Y$ lo que veo es que lo 
que le falta a la educación es libertad. Libertad en el sentido de que efectivamente tenemos que desarrollar y formar personas con capacidad de crítica. Me parece que la desvalorización de la reflexión -ya acusada por Heidegger hace mucho rato en nuestra sociedad occidental- responde en gran parte a lo que está pasando con los niños anglos. $Y$ en algún sentido también nos afecta a nosotros.

Mi pregunta es, en definitiva, al educar, ¿qué pretendemos de los niños que estamos educando?

I. E.: Para ver lo que entrega la educación, pensemos por un momento en la educación de los niños pequeños, ya que es más fácil tomar un ejemplo de los niños pequeños.

Lo más importante es concentrarse alrededor de un tema, escuchar al profesor, leer un texto; también, de vez en cuando, que haya discusión con los amigos y entre los alumnos, pero sobre todo la discusión de la clase con el profesor. En suma: concentración alrededor de un tema, seguir al día siguiente retomando el hilo, no olvidarse de los temas, desarrollar el lenguaje en combinación con la discusión sobre el tema y retener en la mente los datos relevantes durante bastante tiempo. Porque solamente cuando el niño retiene el tema puede darle vueltas, y utilizar ese conocimiento más tarde, para su propio pensamiento. $\mathrm{Y}$ esto debe continuar año tras año, materia tras materia, profesor tras profesor. Y finalmente, al cabo de diez o doce años, hay una acumulación de conocimientos, de palabras, de puntos de vista de conversaciones con unos y otros que forman una base para la reflexión.

La pregunta me hace pensar en un estudio que acabo de leer, de un francés que trabaja con niños adolescentes con problemas de todo tipo. Lo que él dice es que cuando le propone a un grupo de cinco alumnos con grandes problemas que hagan algo, suele recibir dos respuestas inmediatas: "Esto ya lo sé" y "Esto no lo puedo hacer". Ambas actitudes rechazan la actividad y el esfuerzo.

Entonces él comienza cada clase leyéndoles durante unos veinte minutos un texto, casi siempre no contemporáneo, de vez en cuando de la antigüedad, sobre un drama humano, una princesa egipcia o un general ateniense, o algo así. Y después de escuchar la historia, discuten. Eso ya es un esfuerzo... escuchar durante veinte minutos, ya es algo nuevo para ellos. 
Segundo, deja que ellos recompongan la historia juntos, en colaboración, para restituir el sentido de lo que se ha dicho. Entonces tienen que mantener la historia en la cabeza durante diez minutos más. Este proceso además cultiva la colaboración. Los estudiantes tienen que tomar en cuenta lo que dicen los otros —a lo que no están acostumbrados en absoluto-, y deben tomar en cuenta seriamente y colaborar intelectualmente con los otros. Otro logro.

Finalmente, la última parte de la clase consiste en pedirles a los estudiantes que escriban un pequeño comentario que no sea un resumen. La idea es que elijan una parte de lo discutido para hacer un desarrollo que puede ser de diferente tipo. Pero es hacer algo por escrito, es fijarlo por escrito.

Entonces, durante cuarenta minutos han hablado de un tema, desarrollado el lenguaje, mantenido una colaboración, y eso ya es algo.... Y la idea es que precisamente la lectura refleje otra cultura y otra época para que el estudiante logre salir de sí mismo. Hasta para estos alumnos se utiliza el mecanismo de salir de sí mismo, para incorporar algo que refresque a la mente por ser diferente.

Creo que éste es un ejemplo muy extremo, pero en la enseñanza hacemos cosas similares. Una clase se construye sobre ese modelo.

P.: A lo largo de mi vida he trabajo en muchos países, en cualquier orden de escuela, desde Kenia hasta Italia -yo soy italiano-, y ahora soy profesor universitario en Chile. Es muy interesante todo lo que se ha dicho acá, pero me parece que en todo lo que hemos dicho hay un gran ausente: el hombre en cuanto tal. Es decir, me parece que hemos hablado de política, de psicología, pero no hemos hablado de lo humano.

Desde mi experiencia, pienso que la esencia de la educación es una relación de "yo a tú", relación que puede facilitarse u obstaculizarse en los varios sistemas que han ilustrado hasta ahora. Pero me parece que el centro de todo tiene que ser esta relación de "tú a yo".

Quisiera saber si comparte o si tiene algún comentario acerca de esto.

I. E.: No comparto la idea, porque más bien hay otro modelo que sería "el triángulo": con el profesor, el alumno y la materia en cada vértice. La educación no es una relación privada: esa relación de “yo a tú” es lo que tenemos en la amistad, en el amor, en la familia, etc. 
Pero la enseñanza es otra cosa. Hay algo más objetivo, y eso de que el alumno estudie solo no funciona, porque es el alumno en relación con la materia, y muy pocos alumnos logran llegar a eso.

En el pasado la enorme sobreautoridad del profesor le daba demasiado peso en ese triángulo, y muy poco peso al alumno. Lo que corresponde es un "triángulo" y un énfasis equivalente en cada vértice del "triángulo”, diría yo.

P.: Quisiera comentar las últimas dos intervenciones de la profesora Enkvist.

Me parece que dentro de la historia educativa de Suecia, una de las cosas que se enfatizó fueron las reformas en formación docente. Resulta que muchos profesores, por un lado, escogieron lengua y sociedad, por ejemplo, y luego tenían que enseñar química y física, o los que escogieron deportes, tenían que terminar en otra cosa, etc. Me parece que el tema del saber docente es algo que he escuchado poco en este rato. Y creo que es una de las claves.

Ahora, pensando en el ejemplo que acaba de dar Inger Enkvist, creo que esa clase es completamente vygotskyana, de principio a fin. En ese sentido, uno podría decir que es constructivista. Para mí "constructivista" no dice nada. Me parece que son muchas las ideas que influyen a la pedagogía a la vez.

En ese sentido, estoy de acuerdo con Cristián Cox, en que autores españoles —creo particularmente que César Coll-sí han hecho una majamama, una mezcolanza, en esto que han llamado "constructivismo en educación". En psicología esto no se entiende como constructivismo.

Entonces, me parece que decir "constructivismo es igual a peligro”, es una sobresimplificación, porque para que haya -desde el punto de vista vygotskyano- una buena enseñanza, el profesor tiene que saber muy bien su materia. Entonces, para mí, la clave tiene que ver con eso, con la formación no meramente pedagógica, sino que con la formación del conocimiento en la materia.

Hoy en día, en Chile eso es preocupante, porque -por ejemplo- un profesor que hace clases en educación básica, en ciencias, sólo ha tenido un semestre de formación en ciencias, iun semestre!, y tiene que enseñarles a niños de primero a octavo básico ciencias. Es imposible que el profesor que se ha formado un semestre en matemáti- 
cas pueda hacer -en términos vygotskyanos - una buena clase de matemáticas. Eso en un semestre no se logra.

Aparte del aprendizaje de los estudiantes, mi pregunta también es por el aprendizaje en Chile. En este caso, por la gente que estudia pedagogía.

Estoy de acuerdo con Andrea, en que no es una cuestión de la teoría, sino de su aplicación. $Y$ en ese sentido - con esto cierroquisiera dejar en claro que lo que llamaba Arturo Fontaine "el juego" no sucede en las clases chilenas. Si uno investiga lo que sucede en el aula, eso no sucede.

Creo que es importante, en términos de investigación para la formación de docentes, mirar lo que pasa en el aula, porque de lo contrario uno puede estar pensando en cosas que en realidad no son las que suceden acá.

I. E.: Primero: veremos mañana en algunos capítulos del documental "Salir Adelante"* que esto sí sucede en las aulas chilenas.

Segundo, quisiera destacar un aspecto de lo que acaba de decir, que se refiere a la importancia de que el profesor tenga conocimientos de la materia.

Se necesitan bastante pocas teorías del aprendizaje, pero se necesita la materia. Al respecto hay muchas investigaciones, una de ellas es de una alumna china — que ha sacado el doctorado en California, precisamente-, que se llama Liping Ma. Ella ha comparado cómo se les enseña matemáticas a los pequeños chinos y a los pequeños estadounidenses. Y lo hace dándoles a las maestras unas pruebas de matemáticas donde les pide que resuelvan el problema y que inventen un ejemplo adecuado para ese tipo de cálculo. Las maestras chinas sabían todas resolver bien el cálculo, y casi todas sabían inventar un problema que correspondiera al cálculo.

De las maestras norteamericanas, había muchas que no sabían resolver el problema, y solamente una de las maestras incluidas en la investigación pudo encontrar un ejemplo que podría corresponder más o menos al cálculo. Entonces — comenta la doctoranda Liping Malas norteamericanas, que habían estudiado más pedagogía, no sabían

* Se trata del documental realizado por el cineasta chileno David Benavente (al que Inger Enkvist alude en su ensayo que se incluye en esta edición), y del cual se exhibieron en el Cep algunos capítulos al día siguiente, 11 de agosto de 2009. (N. del E.) 
suficientes matemáticas. Por otro lado, las chinas habían tenido un tiempo de estudio más corto, pero todas amaban las matemáticas, y se consideraban muy afortunadas en poder enseñarlas. Yo creo que hay muchos ejemplos así.

El problema con la pedagogía como disciplina universitaria es que no hay una relación clara entre tomar clases de pedagogía y ser buen profesor. Todos sabemos de gente que ha tenido una formación pedagógica, y que son malos profesores. Y sabemos de otros que no la han tenido, y que son buenos profesores. Esos serían casos anómalos, dos o tres en una situación normal en otras profesiones, pero no es así entre el profesorado. Entonces, aquí hay algo que no está funcionando.

P.: Entendiendo la educación - tal como se ha planteado en alguna medida acá- como el intercambio de valores que está a la base, quisiera saber cuál sería el sustrato ideológico, valórico, moral y ético que está detrás de este intercambio cultural y que está sosteniendo el cómo se piensa la educación. Me interesa su opinión sobre el rol del educador, y además sobre la relación humana que se establece, y también el empoderamiento y la conciencia crítica que se logra generar en el alumno.

I. E.: Yo me he formulado esa pregunta. Y estoy intentando elaborar una respuesta a través de la obra de Hannah Arendt, la filósofa judíoalemana que escribió, sobre todo, en el campo de la teoría política y un poco en el campo de la filosofía. Pero uno puede extraer de su obra una filosofía de la educación, que es lo que estoy intentando hacer en este momento.

Para la primera pregunta, ¿qué tipo de intercambio cultural hay aquí? Estamos como en la antropología. Ella dice que partimos desde la situación en que las personas formamos una pluralidad, y somos muchos y somos diferentes. Y esto es ser humano, vivir entre muchos otros que son diferentes. Tampoco queremos tener copias de nosotros mismos, sino que queremos llevarnos bien con gente diferente. Eso es lo que nos gusta, eso es lo que llamamos amistad o amor. Es lo que nos gusta.

Así es que el objeto es el intercambio con otros, que son a la vez iguales y diferentes en la pluralidad, eso es lo que ella dice. 
Lo que es especial con la educación es que — dice- cuando los niños nacen al mundo, son "nuevos" (es la palabra que utiliza). Los adultos que hemos traído a los niños al mundo tenemos una responsabilidad por los niños y por el mundo.

Y si odiamos al mundo, no deberíamos traer niños al mundo. $\mathrm{Y}$ si odiamos a los niños, no deberíamos exponer al mundo a estos niños. Así es que tenemos que amar a los niños y al mundo. Y fomentar en los niños un amor al mundo cuando son pequeños.

A propósito de la palabra "autoridad", que hemos utilizado un poco hoy - para Hannah Arendt-, el profesor que sabe su materia y que tiene el respaldo de una institución puede trabajar con cierta autoridad. Y ella dice algo muy conflictivo también: dice que hay dos maneras para perder la autoridad en un grupo, por ejemplo, de niños: la violencia y la negociación excesiva. Con niños, la manera más rápida en que el profesor pierde su autoridad es utilizar algún tipo de violencia. Al hacerlo, quizá los niños le tengan miedo, pero el miedo genera la mentira y la evitación y otras cosas.

También se pierde la autoridad - y esto va en contra de lo que se suele decir en los manuales pedagógicos hoy en día- si se transa demasiado, porque entonces el profesor se pone en el mismo nivel que el alumno y no asume su responsabilidad. Porque si el alumno elige algo negativo y el adulto acepta esa elección, deja que el alumno se destruya a sí mismo y al ambiente.

Si el alumno necesariamente obtiene lo que quiere del adulto, esta negociación en realidad es “manipulación” y no “negociación”.

Después, Hannah Arendt tiene una idea —no muy aceptada hoy en día - que apunta a que los niños y los adolescentes deben tener un tiempo durante su estudio para estudiar, para formarse. Durante la etapa escolar los niños todavía no conocen bien el mundo. Entonces, hacer que ellos tomen decisiones sobre el mundo, sin conocerlo, es cruel, dice ella.

Es sólo después de ese período, cuando ya son adultos, que se abren a la vida política, social, etc. Y éste es el momento para explorar temas de identidad, de conflictos sociales, etc.

Yo estoy muy deslumbrada por una pensadora que se dedica a pensar de manera tan independiente. Leyéndola me doy cuenta de cuán pocos son los que intentan pensar independientemente. Ella murió en 
1975, han pasado treinta años y todavía es provocadora. Y la educación no es su campo, pero es muy importante e interesante lo que dice.

Respecto del pensamiento crítico, su manera de manejar ese concepto en la educación es comenzar con lo concreto (hemos hablado de lo concreto aquí varias veces), trabajar con los alumnos alrededor de lo concreto. Puede ser un ejemplo, lo concreto no tiene que ser material sino un ejemplo, algo histórico por ejemplo. Si uno utiliza material histórico — dice ella—, la complicación, la complejidad del mundo ya está ahí.

Para terminar - estoy escribiendo sobre esto en este momento, por eso tengo la cabeza llena de lo que dice ella-, Hannah Arendt escribió un artículo sobre The Pentagon Papers, de Nixon y Watergate y compañía, y esto la lleva a una reflexión sobre la mentira. Dice que la mentira es mucho más probable y verosímil porque una persona que prepara una mentira sabe cuál es la situación, sabe lo que espera escuchar el auditor. Y entonces la mentira, en general, no llama la atención, porque es una respuesta preparada para la situación.

Mientras que la verdad, muchas veces, es conflictiva, es difícil, no se adapta bien a los esquemas que uno tiene en la cabeza. Por eso, la verdad provoca mejor el pensamiento y, además, es la verdad.

El concepto de la verdad en el trato entre el profesor y alumno y la valoración de la verdad son algo muy importante, porque lo que vemos ahora es que no se enseña a decir la verdad. Muchos alumnos consideran que esto no es importante. Alguno dice algo para escaparse, para no responder, y les da lo mismo. Después el profesor dice: "Lo que dijiste no fue así...”. Y responden: “Qué más da, no importa...”. Y ahí es cuando hablamos de los valores, de la pluralidad, del intercambio, de lo complejo histórico, y de intentar atenerse a la verdad. Eso es algo importante en la educación.

Palabras clave: reformas del sistema educativo en Suecia; calidad de la educación; nueva pedagogía de la educación; sociología de la educación; igualitarismo; constructivismo; prácticas docentes en Chile, Inger Enkvist. 